\title{
THE REPORT OF THE ECOLOGICAL SOCIETY OF AMERICA COMMITTEE ON THE SCIENTIFIC BASIS FOR ECOSYSTEM MANAGEMENT $^{1}$
}

\author{
Norman L. Christensen (Chair) \\ Nicholas School of the Environment, Duke University, Durham, North Carolina 27708 USA
}

ANN M. BARTUSKA

U.S. Department of Agriculture, Washington, D.C. 20090 USA

JAMES H. BROWN

Department of Biology, University of New Mexico, Albuquerque, New Mexico 87131 USA

STEPHEN CARPENTER

Center for Limnology, University of Wisconsin, Madison, Wisconsin 53706 USA

CARla D' ANTONIO

Department of Integrative Biology, University of California, Berkeley, California 94720 USA

ROBERT FRANCIS

Fisheries Research Institute, University of Washington, Seattle, Washington 98195 USA

JERRY F. FRANKLIN

College of Forest Resources, University of Washington, Seattle, Washington 98195 USA

JAMES A. MACMAHON

Department of Biology, Utah State University, Logan, Utah 84322 USA

REed F. Noss

Department of Fisheries and Wildlife, Oregon State University, Corvallis, Oregon 97330 USA

DAVID J. PARSONS

USDA Forest Service, Leopold Institute, Missoula, Montana 59807 USA

Charles H. Peterson

Institute of Marine Sciences, University of North Carolina, Chapel Hill, North Carolina 27599 USA

MONICA G. TURner

Zoology Department, University of Wisconsin, Madison, Wisconsin 53706 USA

ROBERT G. WOODMANSEE

Rangeland Ecosystem Science, Colorado State University, Ft. Collins, Colorado 80523 USA

Abstract. Ecosystem management is management driven by explicit goals, executed by policies, protocols, and practices, and made adaptable by monitoring and research based on our best understanding of the ecological interactions and processes necessary to sustain ecosystem composition, structure, and function.

In recent years, sustainability has become an explicitly stated, even legislatively mandated, goal of natural resource management agencies. In practice, however, management approaches have often focused on maximizing short-term yield and economic gain rather than long-term sustainability. Several obstacles contribute to this disparity, including: (1) inadequate information on the biological diversity of environments; (2) widespread ignorance of the function and dynamics of ecosystems; (3) the openness and interconnectedness of ecosystems on scales that transcend management boundaries; (4) a prevailing public perception that the immediate economic and social value of supposedly renewable resources outweighs the risk of future ecosystem damage or the benefits of alternative management approaches. The goal of ecosystem management is to overcome these obstacles.

Ecosystem management includes the following elements: (1) Sustainability. Ecosystem management does not focus primarily on "deliverables" but rather regards intergenerational sustainability as a precondition. (2) Goals. Ecosystem management establishes measurable

\footnotetext{
${ }^{1}$ For a copy of this 27 -page report, available for $\$ 4.00$, or for further information, contact The Ecological Society of America, 2010 Massachusetts Avenue, NW, Suite 400, Washington, DC, 20036. Ph: (202) 833-8773; Fax: (202) 833-8775.
} 
goals that specify future processes and outcomes necessary for sustainability. (3) Sound ecological models and understanding. Ecosystem management relies on research performed at all levels of ecological organization. (4) Complexity and connectedness. Ecosystem management recognizes that biological diversity and structural complexity strengthen ecosystems against disturbance and supply the genetic resources necessary to adapt to long-term change. (5) The dynamic character of ecosystems. Recognizing that change and evolution are inherent in ecosystem sustainability, ecosystem management avoids attempts to "freeze" ecosystems in a particular state or configuration. (6) Context and scale. Ecosystem processes operate over a wide range of spatial and temporal scales, and their behavior at any given location is greatly affected by surrounding systems. Thus, there is no single appropriate scale or time frame for management. (7) Humans as ecosystem components. Ecosystem management values the active role of humans in achieving sustainable management goals. (8) Adaptability and accountability. Ecosystem management acknowledges that current knowledge and paradigms of ecosystem function are provisional, incomplete, and subject to change. Management approaches must be viewed as hypotheses to be tested by research and monitoring programs.

The following are fundamental scientific precepts for ecosystem management. (1) Spatial and temporal scale are critical. Ecosystem function includes inputs, outputs, cycling of materials and energy, and the interactions of organisms. Boundaries defined for the study or management of one process are often inappropriate for the study of others; thus, ecosystem management requires a broad view. (2) Ecosystem function depends on its structure, diversity, and integrity. Ecosystem management seeks to maintain biological diversity as a critical component in strengthening ecosystems against disturbance. Thus, management of biological diversity requires a broad perspective and recognition that the complexity and function of any particular location is influenced heavily by the surrounding system. (3) Ecosystems are dynamic in space and time. Ecosystem management is challenging in part because ecosystems are constantly changing. Over time scales of decades or centuries, many landscapes are altered by natural disturbances that lead to mosaics of successional patches of different ages. Such patch dynamics are critical to ecosystem structure and function. (4) Uncertainty, surprise, and limits to knowledge. Ecosystem management acknowledges that, given sufficient time and space, unlikely events are certain to occur. Adaptive management addresses this uncertainty by combining democratic principles, scientific analysis, education, and institutional learning to increase our understanding of ecosystem processes and the consequences of management interventions, and to improve the quality of data upon which decisions must be made.

Ecosystem management requires application of ecological science to natural resource actions. Moving from concepts to practice is a daunting challenge and will require the following steps and actions. (1) Defining sustainable goals and objectives. Sustainable strategies for the provision of ecosystem goods and services cannot take as their starting points statements of need or want such as mandated timber supply, water demand, or arbitrarily set harvests of shrimp or fish. Rather, sustainability must be the primary objective, and levels of commodity and amenity provision must be adjusted to meet that goal. (2) Reconciling spatial scales. Implementation of ecosystem management would be greatly simplified if management jurisdictions were spatially congruent with the behavior of ecosystem processes. Given the variation in spatial domain among processes, one perfect fit for all processes is virtually impossible; rather, ecosystem management must seek consensus among the various stakeholders within each ecosystem. (3) Reconciling temporal scales. Whereas management agencies are often forced to make decisions on a fiscal-year basis, ecosystem management must deal with time scales that transcend human lifetimes. Ecosystem management requires longterm planning and commitment. (4) Making the system adaptable and accountable. Successful ecosystem management requires institutions that are adaptable to changes in ecosystem characteristics and in our knowledge base.

Adaptive management by definition requires the scientist's ongoing interaction with managers and the public. Communication must flow in both directions, and scientists must be willing to prioritize their research with regard to critical management needs. Scientists have much to offer in the development of monitoring programs, particularly in creating sampling approaches, statistical analyses, and scientific models. As our knowledge base evolves, scientists must develop new mechanisms to communicate research and management results. More professionals with an understanding of scientific, management, and social issues, and the ability to communicate with scientists, managers, and the public are needed.

Ecosystem management is not a rejection of an anthropocentric for a totally biocentric worldview. Rather it is management that acknowledges the importance of human needs while at the same time confronting the reality that the capacity of our world to meet those needs in perpetuity has limits and depends on the functioning of ecosystems. 


\section{INTRODUCTION}

We should manage so as not to deny future generations the opportunities and resources we enjoy today.

A century ago, only a few prescient individuals were concerned about the sustainability of the variety of ecosystems that provide the commodities and services upon which humans depend. Large expanses of "the frontier" remained, the sea was considered unexplored and underexploited, and the natural world was seen solely as a cornucopia whose raison d'être was to provision human needs, as well as an infinite sink for human wastes and pollutants.

During this century, human populations, along with their demands for space, commodities, and amenities from ecosystems, have increased by over fivefold (e.g., Karlin 1995). At the same time, evidence has mounted that there are limits to the stress such systems can withstand and still remain viable. We have witnessed the collapse of agricultural ecosystems in the southeastern United States and midwestern "Dust Bowl," and watched the spread of desert into rangeland in the Southwest. That the frontier is gone is nowhere more vividly symbolized than in the western forests where our wish to sustain harvests from dwindling supplies of old-growth timber has run headlong into our legislated commitment to preserve the diverse biota comprising those ancient woods. Marine fisheries, once thought to be inexhaustible, are now impoverished, and access to these resources has become a matter of serious international dispute. The impact of forest management activities on breeding habitat for migratory fishes has highlighted the reality that the sustainability of many ecosystems depends on connections to other systems that extend well beyond individual ownerships, traditional borders of management jurisdiction, and even international boundaries.

We should manage so as not to deny future generations the opportunities and resources we enjoy today. At its core, ecosystem management assumes that intergenerational sustainability must be a precondition rather than an afterthought, not only for the continued production of "goods" or commodities, but also for the maintenance of critical "services" that ecosystems provide (Box 1). Goods represent those items that we commonly buy and sell and have monetary value in the market place. Society also depends on the services that ecosystems provide such as clean air and water, which we value but are not typically given monetary value. All of these goods and services derive from a diverse array of functions performed by ecosystem.

We rely on highly managed ecosystems such as croplands, estuarine aquacultural systems, or forest plantations for producing ecosystem goods; however, the sustainability of such intensively managed ecosystems is strongly dependent on the matrix of less managed
Box 1. Ecosystem goods and services. Healthy ecosystems perform a diverse array of functions that provide both goods and services to humanity. Here, goods refer to items given monetary value in the market place, whereas the services from ecosystems are valued, but rarely bought or sold.

Ecosystem processes include:

- Hydrologic flux and storage

- Biological productivity

- Biogeochemical cycling and storage

- Decomposition

- Maintenance of biological diversity

Ecosystem "goods" include:

- Food

- Construction materials

- Medicinal plants

- Wild genes for domestic plants and animals

- Tourism and recreation

Ecosystem "services" include:

- Maintaining hydrological cycles

- Regulating climate

- Cleansing water and air

- Maintaining the gaseous composition of the atmosphere

- Pollinating crops and other important plants

- Generating and maintaining soils

- Storing and cycling essential nutrients

- Absorbing and detoxifying pollutants

- Providing beauty, inspiration, and research

(Modified from Ehrlich and Ehrlich 1991, Lubchenco et al. 1993, and Richardson 1994)

ecosystems in which they are embedded (e.g., Lubchenco et al. 1993).

In recent years, sustainability has become an explicitly stated, even legislatively mandated, goal of management agencies charged with the stewardship of natural resources. In practice, however, management strategies and tactics have often focused on maximizing short-term yield and economic gain, rather than longterm sustainability. Several factors contribute to this disparity between goals and practices, including: (1) gross undersampling of nearly all environments and consequent poverty of information on their biological diversity; (2) widespread ignorance of the functioning and dynamics of ecosystems; (3) the openness and interconnectedness of ecosystems on spatial and temporal scales that exceed greatly the bounds of any management authority; and (4) a prevailing public perception that exploitation of supposedly renewable resources 
Box 2. Selected definitions of ecosystem management.

... regulating internal ecosystem structure and function, plus inputs and outputs, to achieve socially desirable conditions.

(Agee and Johnson 1988)

... the careful and skillful use of ecological, economic, social, and managerial principles in managing ecosystems to produce, restore, or sustain ecosystem integrity and desired conditions, uses, products, values, and services over the long term.

(Overbay 1992)

... the strategy by which, in aggregate, the full array of forest values and functions is maintained at the landscape level. Coordinated management at the landscape level, including across ownerships, is an essential component.

(Society of American Foresters 1993)

. . . a strategy or plan to manage ecosystems for all associated organisms, as opposed to a strategy or plan for managing individual species.

(Forest Ecosystem Management Team 1993)

... the optimum integration of societal values and expectations, ecological potentials, and economic plus technological considerations.

(Eastside Forest Health Assessment Team 1993)

... a resource management system designed to maintain or enhance ecosystem health and productivity while producing essential commodities and other values to meet human needs and desires within the limits of socially, biologically, and economically acceptable risk.

(American Forest and Paper Association 1993)

... integrating scientific knowledge of ecological relationships within a complex sociopolitical and values framework toward the general goal of protecting native ecosystem integrity over the long term.

(Grumbine 1994)

... integration of ecological, economic, and social principles to manage biological and physical systems in a manner that safeguards the ecological sustainability, natural diversity, and productivity of the landscape.

(Wood 1994)

has immediate economic and social value sufficient to outweigh the risks of damage to future ecosystem services or any alternative management goals.

More than a century of ecological research and natural resource management experience has taught us that ecosystems are far more complex and difficult to manage than was thought at the time that resource management agencies such as the Forest Service, National Park Service, and National Marine Fisheries Service were established. With limited understanding of the importance of diversity and complexity in ecological systems, utilitarian management has generally proceeded on the notion that we can simplify the structure and composition of ecosystems to achieve efficient production of specific goods such as timber, fish, or agricultural crops at no risk to sustainability. Our grossly inadequate understanding of the important role of natural disturbance processes to sustained ecosystem function certainly supported so-called "object-oriented" management protocols for our wilderness parks that denied their ever-changing character (Agee and Johnson 1988).

As with all of the sciences, ecological understanding and models of ecosystem functioning are provisional and subject to change. However, mechanisms for adjustment of management goals and strategies as ecosystems change and as our knowledge base improves are often limited or absent. Recent reports of the $\mathrm{Na}$ tional Academy of Sciences (National Research Council $1990,1992 a$ ) have emphasized the negative consequences of this limited ability to adapt to changing conditions and new information.

\section{Defining Ecosystem Management}

No fewer than 18 Federal agencies have committed to the principles of ecosystem management (Congressional Research Service 1994). Similar commitments have been made by a variety of state and local land managers, nongovernmental organizations, and corporations involved in natural resource management. Furthermore, elements of ecosystem management are mandated for federal lands in a number of important pieces of legislation (Appendix 1). Nevertheless, there is little agreement on the exact meaning of this phrase (Box 2). This diversity of definitions brings to mind the fable of the six blind men and the elephant, with each definition reflecting the specific perspective, agen$\mathrm{da}$, or interest of the author. However, a cynic might claim that, rather than touching different parts of the ecosystem management elephant, each "blind man" is grabbing a different item and claiming to have grabbed an elephant.

So, what is the elephant? Franklin (1996) suggested that ecosystem management is ". . . managing ecosystems so as to assure their sustainability." Sustainability is indeed the central goal or value of ecosystem management. Notions of sustainability are at least implicit in other management protocols or schemes; however, the focus is typically on sustaining the delivery of desired goods and services. Ecosystem management is management driven by explicit goals, executed by policies, protocols, and practices, and made adaptable by monitoring and research based on our best understand- 
ing of the ecological interactions and processes necessary to sustain ecosystem structure and function. Ecosystem management does not focus primarily on the "deliverables" but rather on sustainability of ecosystem structures and processes necessary to deliver goods and services.

Some might claim that, because we have been involved in management activities in ecosystems, "we have been doing ecosystem management all along." However, the mere fact that one is involved in the management or manipulation of an ecosystem such as a lake or a watershed does not by itself qualify as ecosystem management because essential components of ecosystem management may be lacking.

Ecosystem management must include the following: (1) long-term sustainability as fundamental value, (2) clear, operational goals, (3) sound ecological models and understanding, (4) understanding complexity and interconnectedness, (5) recognition of the dynamic character of ecosystems, (6) attention to context and scale, (7) acknowledgment of humans as ecosystem components, and (8) commitment to adaptability and accountability.

1) Sustainability. Ecosystem management assumes intergenerational sustainability (Lubchenco et al. 1991) as a precondition for management rather than an afterthought. Thus, the manager accepts the responsibility up front of managing in such a way as to ensure provision of the opportunities and resources we enjoy today to future generations.

2) Goals. Ecosystem management is as applicable to intensive utilitarian objectives as it is to the conservation of pristine wilderness; however, goals should not focus exclusively on "deliverables" such as board feet of timber, total catch, or visitor days. Goals must be explicitly stated in terms of specific "desired future trajectories" and "desired future behaviors" for the ecosystem components and processes necessary for sustainability. Furthermore, these goals should be stated in terms that can be measured and monitored.

3) Sound ecological models and understanding. Ecosystem management is based on sound ecological principles and emphasizes the role of processes and interconnections. Ecosystem management should be rooted in the best current models of ecosystem function. The name "ecosystem management" is confusing and has been taken by some to suggest that only science done at the ecosystem level is relevant. Ecosystem management depends on research performed at all levels of organization, from investigations of the morphology, physiology, and behavior of individual organisms, through studies of the structure and dynamics of populations and communities, to analysis of patterns and processes at the level of ecosystems and landscapes.

4) Complexity and connectedness. The importance of ecosystem complexity and the vast array of interconnections that underlie ecosystem function is cer- tainly one of the most important lessons of 10 decades of ecological research and natural resource management experience (Peterson 1993). Biological diversity and structural complexity of ecosystems are critical to such ecosystem processes as primary production and nutrient cycling. Complexity and diversity also impart resistance to and resilience from disturbance, and provide the genetic resources necessary to adapt to longterm change. Extractive or utilitarian management systems such as agriculture, aquaculture, or plantation forestry that explicitly reduce complexity and diversity in order to increase productivity of particular ecosystem components may be deficient in key ecosystem processes and, therefore, less stable and less sustainable than intact and diverse natural ecosystems.

With complexity comes uncertainty. Some of our uncertainty regarding or lack of precision in predicting ecosystem behavior derives from the fact that we do indeed have more to learn. However, we must recognize that there will always be limits to the precision of our predictions set by the complex nature of ecosystem interactions and strive to understand the nature of those limits. Ecosystem management cannot eliminate surprises or uncertainty; rather, it acknowledges that, given sufficient time and space, unlikely events are certain to happen.

5) Recognition of the dynamic character of ecosystems. Sustainability does not imply maintenance of the status quo. Indeed, change and evolution are inherent characteristics of ecosystems, and attempts to "freeze" ecosystems in a particular state or configuration are generally futile in the short term and certainly doomed to failure in the long term. Crises associated with the management of our forests, fisheries, and wildlife have driven home the points that individual resources cannot be managed outside of the context of the full array of ecosystem components and processes and that the spatial and temporal domains of critical ecological processes are rarely congruent with the spatial boundaries and temporal schedules of management.

6) Context and scale. Ecosystem processes operate over a wide range of spatial and temporal scales, and their behavior at any given location is very much affected by the status and behavior of the systems or landscape that surrounds them (e.g., Levin 1992). There is no single appropriate scale or time frame for management. Our ignorance of the importance of processes operating over ranges of spatial and temporal scale permitted society to define the boundaries of management jurisdictions with little or no reference to such processes. The importance of context in determining the behavior of ecosystems at a particular location has been the impetus for the advocacy of a "landscape approach" in terrestrial ecosystems (e.g., Noss 1983, Noss and Harris 1986) and the development of the "large marine ecosystem concept" (Sherman et al. 1990).

7) Humans as ecosystem components. Ecosystem 
management acknowledges the role of humans, not only as the cause of the most significant challenges to sustainability, but as integral ecosystem components who must be engaged to achieve sustainable management goals (McDonnell and Pickett 1993, Peterson 1993). Human effects on ecosystems are ubiquitous. Although we should strive to reduce deleterious impacts, current trends in population growth and demand for natural resources will undoubtedly require more intensive and wiser management, particularly to support human needs in a sustainable way. Thus, identifying and engaging stakeholders in the development of management plans is a key ecosystem management strategy. Humans who are part of the ecosystems will, of necessity, define the future of those ecosystems.

Ecosystem management is a necessary but insufficient condition for achieving long-term sustainability. We must also address such daunting issues as human population growth, poverty, and human perceptions regarding the use of energy and natural resources.

8) Adaptability and accountability. As in all areas of science, current models and paradigms of ecosystem function are provisional and subject to change. Ecosystem managers must acknowledge that our knowledge base is incomplete and subject to change. Management goals and strategies must be viewed as hypotheses to be tested by research and monitoring programs that compare specific expectations against objective measures of results (Holling 1978, Walters 1986, Likens 1992).

Adaptability and accountability are central elements of ecosystem management. Managers must be able to adapt to the unique features or needs of a particular area and to inevitable temporal changes as well. Management must also be able to adapt to new information and understanding. To be adaptable and accountable, management objectives and expectations must be explicitly stated in operational terms, informed by the best models of ecosystem functioning, and tested by carefully designed monitoring programs that provide accessible and timely feedback to managers. Public understanding and acceptance of the experimental nature of all natural resource management are critical to the implementation of ecosystem management protocols.

Our own impacts on this planet's ecosystems make such adaptive management all the more compelling. The earth's ecosystems are being modified in new ways and at faster rates than at any other time in their nearly four billion year history. These new and rapid changes present significant challenges to our ability to predict the inherently uncertain responses and behaviors of ecosystems.

\section{Ecological SCIENCE AS THE Basis FOR ECOSYSTEM MANAGEMENT}

What is an ecosystem?

An ecosystem is defined as "a spatially explicit unit of the Earth that includes all of the organisms, along with all components of the abiotic environment within its boundaries" (Likens 1992). Although the word "ecosystem" is appropriately attributed to Sir Arthur Tansley (1935), underlying concepts such as hierarchical organization of individuals, populations, and communities and the functional connections between the biota and the abiotic environment are implicit in the writings of Möbius (1877), Forbes (1887), Cowles (1899), and Clements (1916), among others. E. P. Odum and H. T. Odum, through their many papers and books, moved the ecosystem concept into the mainstream of ecological science (see Hagen 1992 and Golley 1993 for recent reviews of the history of ecosystem ecology).

Managed ecosystems can be arrayed along a gradient of impacts and inputs or subsidies (Box 3). To sustain heavily managed ecosystems such as cities, heavy subsidies of energy and materials must be imported from other ecosystems. The need for such subsidies diminishes as the intensity of use diminishes.

Nature has not provided us with a natural system of ecosystem classification or rigid guidelines for boundary demarcation. Ecological systems vary continuously along complex gradients in space and are constantly changing through time. Furthermore, no ecosystem, including the entire biosphere, is closed with respect to exchanges of organisms, matter, and energy. Nevertheless, ecologists do not define ecosystem boundaries in an arbitrary fashion.

Recognizing that ecosystem functioning includes inputs, outputs, and cycling of materials and energy, as well as the interactions of organisms, ecosystem scientists define ecosystem boundaries operationally so as to most easily monitor, study, or manipulate these processes. Thus, depending on the process of central interest, a dung pile or whale carcass are ecosystems as much as a watershed or a lake.

Boundaries defined for the study or management of one issue, process, or element are often inappropriate for the study of others. For example, watersheds represent a useful unit for the study of water and nutrient fluxes driven by hydrology, but may not be ideal for studies of trophic dynamics in areas where animals move over large distances. Likewise, they represent a useful unit for management of stream water quality but are less useful for the management of large vertebrate herbivores or carnivores.

It is desirable, but not always possible to define the boundaries of natural resource jurisdictions so as to manage most easily the processes necessary to achieve our management goals. However, it is the arbitrariness of jurisdictional boundaries relative to key ecological processes that mandates a broad view of ecosystem management.

\section{Scales of organization}

Ecosystem-level science such as studies of entire watersheds, estuaries, or ocean gyres has provided many important basic concepts to ecosystem management; 
Box 3. A conceptual framework for ecosystem management goals, inputs, and outputs.

\begin{tabular}{|c|c|c|c|c|}
\hline Category & $\begin{array}{l}\text { Ecosystem type and } \\
\text { human use }\end{array}$ & $\begin{array}{c}\text { Intensity and goals of } \\
\text { management }\end{array}$ & Inputs & Outputs \\
\hline Intensive & $\begin{array}{l}\text { Urban } \\
\text { Intensive agriculture, } \\
\quad \text { aquaculture, and } \\
\quad \text { suburban } \\
\text { Plantation forestry } \\
\text { Managed pasture }\end{array}$ & $\begin{array}{l}\text { Intensive management } \\
\text { to provide food and } \\
\text { shelter for human } \\
\text { use }\end{array}$ & $\begin{array}{l}\text { Heavy subsidies of en- } \\
\text { ergy (fossil fuels), } \\
\text { materials (fertilizers, } \\
\text { metal, and wood), } \\
\text { and human labor }\end{array}$ & $\begin{array}{l}\text { Manufactured products } \\
\text { Pollutants and toxins } \\
\text { Food and water }\end{array}$ \\
\hline Seminatural & $\begin{array}{l}\text { Managed forestry, graz- } \\
\quad \text { ing, wildlife, and } \\
\quad \text { fisheries } \\
\text { Forest } \\
\text { Grassland } \\
\text { Woodland } \\
\text { Shrublands } \\
\text { Lakes } \\
\text { Streams/rivers } \\
\text { Wetlands } \\
\text { Estuaries } \\
\text { Oceans } \\
\text { Extraction preserves }\end{array}$ & $\begin{array}{l}\text { Moderate management } \\
\text { for sustained pro- } \\
\text { duction of natural } \\
\text { resources and for } \\
\text { maintenance of eco- } \\
\text { system processes }\end{array}$ & $\begin{array}{l}\text { Moderate inputs of en- } \\
\text { ergy, materials, and } \\
\text { human labor }\end{array}$ & $\begin{array}{l}\text { Harvested natural re- } \\
\text { sources; timber, live- } \\
\text { stock, fish, wildlife, } \\
\text { water, minerals, fos- } \\
\text { sil and fuels } \\
\text { Ecosystem services }\end{array}$ \\
\hline Natural & $\begin{array}{l}\text { All kinds } \\
\text { Reserves and wild areas }\end{array}$ & $\begin{array}{l}\text { Minimal management to } \\
\text { maintain biological } \\
\text { and habitat diversity, } \\
\text { integrity of natural } \\
\text { ecosystem processes, } \\
\text { and esthetic values }\end{array}$ & $\begin{array}{l}\text { Minimal management to } \\
\text { maintain near-natural } \\
\text { conditions }\end{array}$ & $\begin{array}{l}\text { Recreational uses } \\
\text { Ecosystem services }\end{array}$ \\
\hline
\end{tabular}

however, an understanding of populations, communities, and landscapes is no less relevant to sustainable management (Box 4). Challenges, such as the management of wildlife populations or development of a recovery plan for an endangered species, may present themselves at one scale of organization, but a complete understanding or resolution of issues usually requires integration across several scales and levels of organization. To determine mechanisms, we must often investigate processes operating at lower levels of organization (say physiology or reproductive biology in the endangered species populations) as well as appreciate the context or higher levels of organization within which the processes operate (O'Neill et al. 1986).

Our ignorance of the importance of processes operating over wide ranges of spatial and temporal scales permitted us to define the boundaries of management jurisdictions with little or no reference to such processes. Rivers may provide convenient boundaries between countries, counties, and other political jurisdictions but, because they bisect watersheds, they are very poor boundaries for managing most ecosystem processes. The 200 -mile $(323 \mathrm{~km})$ territorial fishing limits were established with little reference to the behavior of the resource to be managed or the processes affecting those resources. Finally, budgeting strategies that are focused on fiscal years or the timing of political elections often drive short-term decisions regarding natural resource use that are not congruent with processes that operate over decades and centuries.

\section{Ecosystem function depends on its structure, diversity, and integrity}

While human interests may focus on a relatively small subset of the organisms or processes operating in an ecosystem, the overall complexity of such systems is critical to their sustainability. Thus, maintenance of biological diversity is an integral component of ecosystem management plans. Biological diversity is the variety of life and its processes, including the variety of living organisms and the genetic differences among them, as well as the variety of habitats, communities, ecosystems, and landscapes in which they occur (Keystone Center 1991). Included in this definition of biological diversity is a recognition of the importance of biotically derived physical structures such as logs and corals.

Biological diversity is central to the productivity and sustainability of the earth's ecosystems. Organisms, biological structures, and processes are the means by which the physical elements of the ecosystem are transformed into the goods and services upon which humankind depends. Specific examples of the role of biodiversity in ecosystem functioning include providing for (1) essential processes, (2) ecosystem resistance to and recovery from disturbances, and (3) adaptability to longterm changes in environmental conditions. There is an extensive literature on the recognized or potential importance of individual species as wildlife or natural resources (e.g., Wilson 1992) so we emphasize the contribution of biodiversity to ecosystem processes. 
Box 4. Connections between population dynamics and ecosystem processes: trophic cascades in lakes. To address ecosystem-level processes, we must understand the dynamics of lower levels of ecological organization such as communities and populations.

Trophic cascades are striking illustrations of the links between population dynamics and ecosystem processes (Paine 1980). Big changes in fish populations at the top of the food web can alter planktivory, herbivory, primary productivity, and nutrient cycling rates in lakes (Carpenter and Kitchell 1993). The changes in fish populations that trigger cascades can be caused by harvesting, fish management, species introductions, fish kills, or recruitment events. Although nutrient inputs are the principal driver of lake ecosystem productivity, variability in the food web accounts for a large fraction of the variance in production that cannot be explained by nutrients (Carpenter and Kitchell 1993).

Biomanipulation is the deliberate creation and maintenance of trophic cascades to improve water quality in lakes (Shapiro et al. 1975, Gulati et al. 1990, Kitchell 1992). Biomanipulation can also improve sport fishing (Kitchell 1992). However, outcomes of biomanipulation field trials have been varied and may depend on magnitude of nutrient load, depth, availability of refuges for herbivores, and the extent to which zooplanktivorous fish can be harvested or controlled by piscivores (Gulati et al. 1990). Increased harvest of piscivores by sport anglers may foil biomanipulation in North American lakes (Johnson and Carpenter 1994). Thus biomanipulation of lakes sometimes succeeds in improving water quality, and other times fails. Understanding the failures represents an important challenge for improvement of lake management.

Links between populations and ecosystem processes influence most of earth's environments (Jones and Lawton 1994). Analogs of biomanipulation may be possible in some terrestrial and marine ecosystems, but these are largely unexplored and we should be cautious at this time.

Many of the numerous and important roles of the variety of species in carrying out ecosystem processes are obvious. Photosynthesis, the capture of physical energy and its conversion to organic structures is the primary basis for primary productivity on earth. Another critical role of organisms is in decompositionthe breakdown of organic structures into their physical elements, including mineral nutrients and energy. Organisms create structures and communities that interact with and alter the physical world and provide habitat for other organisms that carry out additional processes. This biotic complexity has important influences on the hydrologic cycle, through condensation, interception, and evapotranspiration, and on geomorphic processes, such as erosion.

A simplistic emphasis on the roles species play in ecosystems may lead some to ask, "how many species are needed to maintain key ecosystem processes," the implication being that we could sustainably manage for some specific number or set of species. This question presumes that: (1) we know all of the individual processes or roles that comprise overall ecosystem functioning; (2) species within an ecosystem are analogous to job categories within a factory and there is a oneto-one overlay of species and specific processes; (3) ecosystems do not change in ways that influence which species are best able to carry out key roles. These assumptions are clearly not met in any ecosystems. We must acknowledge the importance of complexity of species interactions that underlie ecosystem functioning and the role that diversity plays in maintaining processes across complex environmental gradients through space and time.

Biological diversity provides for both stability (resistance) to and recovery (resilience) from disturbances that disrupt important ecosystem processes. Resistance often results from complex linkages among organisms, such as food webs that provide alternate pathways for flows of energy and nutrients. The presence of numerous organisms with similar capabilities, sometimes inappropriately viewed as redundancies, also provides for ecosystem stability as well as optimal functioning. For example, the presence of numerous fungal species capable of forming mycorrhizae in a terrestrial ecosystem buffers it against the loss of individual species and makes total loss of mycorrhizal functioning unlikely; the presence of numerous species also makes it more likely that important processes (such as moisture and nutrient uptake) will be optimized in the face of seasonal, annual, and longer term climatic variations.

Diversity-related resistance is particularly relevant to the management of agricultural and forest ecosystems because it can retard the spread of species-specific pathogens and "pest" insects. Although monocultures may result in high levels of production of specific products or resources, they present much higher risks from such infestations than more complex systems. The importance of species diversity to the ability of ecosystems to recover ecosystem processes such as productivity following a disturbance or perturbation has been convincingly demonstrated in long-term studies of productivity responses to drought in grasslands (Tilman and Downing 1994).

Long-term adaptations of ecosystems to changes in climate and other environmental variables are strongly dependent upon available biological diversity. Obviously, greater numbers of species and greater genetic 
variability within species provide for a larger number of biological building blocks for ecosystem response and species evolution. Given ever-changing environments, the capacity to adapt is central to the long-term sustainability of ecosystem function. Long-term pollen profiles suggest that relatively unimportant species restricted to particular microsites during one climatic regime may become important and more widespread as the climate shifts (e.g., Delcourt and Delcourt 1991). The reservoir of genetic diversity within individual species and populations is clearly central to their ability to adapt to environmental change (e.g., Antonovics 1968). In view of this, focus on so-called "improved" genotypes of crop plants and forest trees has raised concern regarding the loss of genetic diversity that might be important if the same species are to be maintained under future conditions.

Uncertainties regarding the distribution and functional importance of many species and ecosystem elements, as well as our limited understanding of the complex relationships of organisms to ecosystem structure and function, argue for a highly conservative approach to biodiversity retention. The first issue goes far beyond our inadequate catalog of species to the fact that we are still in the process of recognizing whole ecosystems and subsystems and their constituent organisms and functions. Examples include the recent recognition of the biological diversity and ecosystems associated with deep marine thermal vents, the hyporheic zones of streams and rivers, terrestrial belowground (soil) environments, and high forest canopies. Much new information is emerging on the second issue, but our understanding of interrelationships is still highly incomplete. Consider, for example, that the importance of the dead tree and its derivative structures has only recently been recognized by foresters and forest ecologists (see Box 5).

The redistribution of species across the globe is one of the most significant human impacts on ecosystems. The negative consequences of exotic species in both natural and managed ecosystems (e.g., Vitousek 1990) stand as stark testimony to the fact that the contribution of biological diversity to ecosystem functioning is not merely a matter of the number and kinds of species present (Box 6).

In the short term, ecosystem management that is focused on the maintenance of biological diversity and ecosystem complexity may be seen to have "economic opportunity costs" in relation to resources not immediately exploited or compromises to commodity production. History has demonstrated that overexploitation of resources resulting in diminished diversity often has both ecological and economic long-term opportunity costs that far exceed the short-term benefits. Attention to these latter costs is at the core of ecosystem management's focus on sustainability. The fact that long-term costs are usually more difficult to quantify than short-term benefits in no way diminishes their importance.

Management that acknowledges the significance of biological diversity is difficult because such diversity is itself a dynamic property of ecosystems affected by variations in spatial and temporal scale. On a relatively local scale, such as a hectare of forest or a small portion of an estuary, species populations may rise, fall, or even go locally extinct as environments change. On a regional scale species populations are less variable because of the connections among habitats and the ability of species to migrate and reestablish.

Fragmentation of landscapes effectively reduces the size of habitat units as well as diminishing habitat continuity. The results are that populations are at greater risk of local extinction because of reduced population sizes and that such extinctions have a greater likelihood of being permanent because of impediments to migration. Thus, management of species' populations and biological diversity requires a landscape-scale perspective and recognition that the complexity and functioning of any particular location is influenced heavily by the nature of the landscape (or seascape) that surrounds it.

\section{Ecosystems are dynamic in space and time}

Ecosystem management is challenging in part because we seek to understand and manage areas that change. The species assemblages observed today in many terrestrial and freshwater ecosystems are relatively recent (e.g., Delcourt and Delcourt 1991). Many have formed only in the last $10000 \mathrm{yr}$ and reflect individual species' responses to changes in the global environment. We are just beginning to understand the complexity and scales of change that occur in marine ecosystems ranging from seasonal variations in currents and sea temperature, to periodic events like the El Niño/Southern Oscillation cycle, to long-term changes and large-scale changes, such as those driven by variations in salinity and ocean temperature.

Most observable and detectable ecosystem dynamics occur against a backdrop of continuous long-term change. Over shorter time scales (e.g., decades to centuries), the patterns apparent on many landscapes are influenced by natural disturbances (e.g., Watt 1947 , Connell and Slatyer 1977, Bormann and Likens 1979, Sousa 1979, White 1979, Mooney and Godron 1983, Pickett and White 1985, Turner 1987, Baker 1989b). Disturbances reset succession within all or a portion of an ecosystem, leading to mosaics of successional patches of different ages within and across landscapes. The importance of such patch dynamics to ecosystem structure and functioning has been demonstrated in a variety of situations including marine intertidal ecosystems (Sousa 1979, Paine and Levin 1981), oldgrowth forests of New England (Foster 1988), and subtropical pine and hardwood forests of central Florida (Myers 1985). 


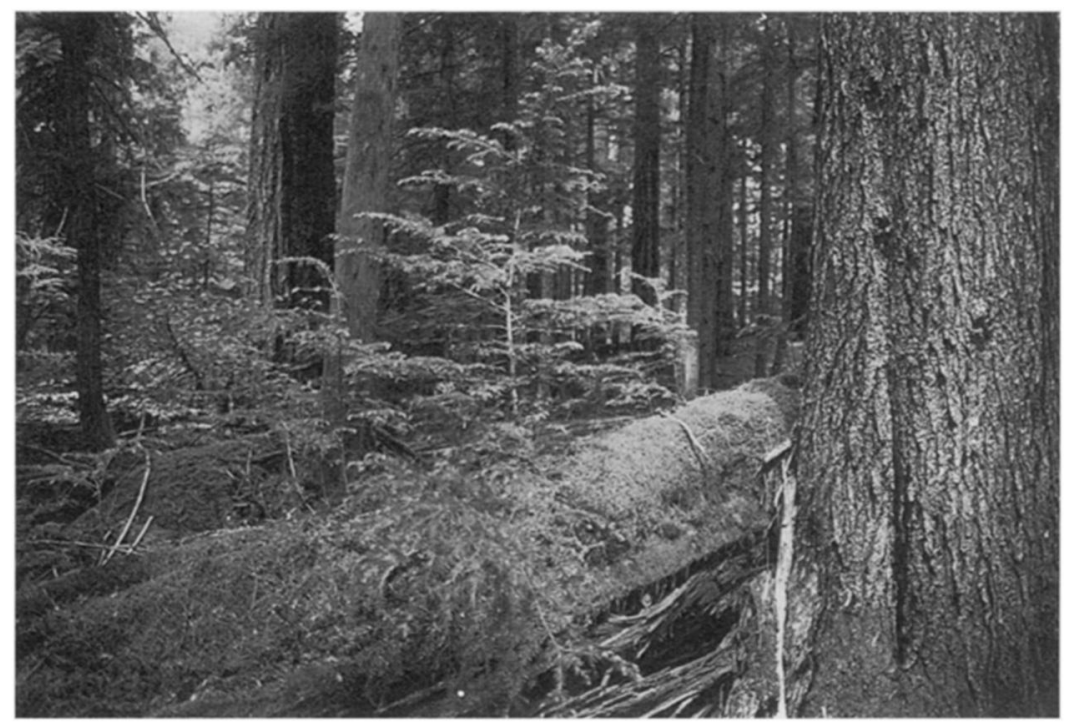

Box 5. Structural diversity and ecosystem function. The structural complexity and diversity of ecosystems directly influence the pattern and rate of many ecosystem processes as well as providing habitat for organisms that maintain important processes. Structural complexity in natural forests includes trees of varying size, condition, and species, standing dead trees, and logs and woody debris on the forest floor, as well as multiple canopy levels and canopy gaps. This structural complexity is critical in providing unique habitats for a large array of organisms, many of which have highly specialized habitat requirements. Some of these organisms carry out key ecosystem functions. For example, lichens dwelling in the forest canopy convert atmospheric nitrogen into biologically useful forms. Structural complexity of forests is also itself important in maintaining and regulating processes, such as aspects of the hydrologic cycle.

Ecosystem management concepts applied to forests recognize the importance of compositional and structural diversity to sustainability as well as short-term production of goods and services. Maintenance and restoration of structurally diverse forests are major objectives. Techniques include use of a wider variety of tree species, provision for standing dead trees and down logs, and silvicultural treatments to create structural diversity. Partial cutting-retention of live and dead tree structures at time of harvestis, in many areas, replacing traditional clear-cutting practices which effectively eliminated structural legacies that provide continuity from one disturbance to the next.

Change is the normal course of events for most ecological systems (Connell and Sousa 1983). The science of ecology increasingly is recognizing the dynamic nature of ecological systems and is embracing a broader view of natural dynamics (see Lubchenco et al. 1991). However, some discussion of the concept of equilibrium is warranted because past resource management decisions have often been based on the assumption that there is some constant or desirable ecological state. The notion of equilibrium in ecological systems has inspired a long history of interest and controversy (e.g., Egerton 1973, Bormann and Likens 1979, Connell and Sousa 1983).

The properties that have been used to evaluate equilibrium fall into two general categories (Turner et al., in press): persistence (i.e., nonextinction) and constancy (i.e., no change or minimal fluctuation in numbers, densities, or relative proportions). Persistence might refer to species, as emphasized in many population-oriented models (e.g., DeAngelis and Waterhouse 1987), or the presence of all successional stages in a landscape (e.g., Romme 1982). Constancy may refer to the number of species (e.g., MacArthur and Wilson 1967), the density of individual species (e.g., May 1973), the standing crop of biomass (e.g., Bormann and Likens 1979), or the relative proportions of seral stages on a landscape (e.g., Romme 1982, Baker $1989 a, b)$. Botkin and Sobel (1975) suggested that a system that changes but remains within bounds is a stochastic analog of equilibrium that is much more suitable for ecological systems. Empirical studies have increasingly demonstrated either a lack of equilibrium (e.g., Romme 1982, Baker 1989a, b) or equilibrium conditions that are observed only at particular scales of time and space (e.g., Allen and Starr 1982, O'Neill et al. 1986). 
The concept of "homeorhesis" (see O'Neill et al. 1986), the tendency of a perturbed system to return to its preperturbation trajectory or rate of change rather than "homeostasis," the tendency to return to some predisturbance state, seems appropriate for ecological systems. Homeorhetic stability implies return to normal dynamics rather than return to an artificial "undisturbed" state. Ecosystem stability can also be thought of in terms of the rate of return after perturbation (resilience or "adjustment stability," Margalef 1968) and the ability of an ecosystem to resist the forces of change acting on it (resistance, or "resistance stability," Sutherland 1974).

Ecological systems do not exhibit an undisturbed "state" that can be maintained indefinitely. Rather, they exhibit a suite of behaviors over all spatial and temporal scales, and the processes that generate these dynamics should be maintained. Thus, Holling (1996) has suggested that ecosystem resilience should be viewed as the magnitude of disturbance that can be absorbed before the variables and processes that control behavior change.

The argument often arises that certain intensive management practices such as fishing or logging simulate the effects of and are reasonable surrogates for natural processes such as predation or fire. At a superficial level, there are indeed some similarities. For example, logging can (though not always) have the effect of reducing flammable fuels (e.g., Lippke and Oliver 1993). If fire's only functional role on landscapes was organic matter oxidation and fuel reduction, then logging might be viewed as a replacement for wildfire. However, the various impacts of fire on such processes as nutrient transfer, and postfire energy balance, as well as the variety of so-called "legacies" such as woody debris and snags (Franklin 1993) that persist from one disturbance cycle to the next, differ greatly from those of logging. Thus, the substitutability of human management for natural disturbance must be understood in the context of management goals and impacts on the full array of ecosystem processes.

Extreme fluctuation is abnormal in most ecosystems and, when caused by human activity, is what often threatens ecosystem functioning. As pointed out by Pickett et al. (1992):

The new paradigm in ecology can, like so much scientific knowledge, be misused. If nature is a shifting mosaic or in essentially continuous flux, then some people may wrongly conclude that whatever people or societies choose to do in or to the natural world is fine. The question can be stated as, "If the state of nature is flux, then is any human-generated change okay?". . . The answer to this question is a resounding "No!" . . . Human-generated changes must be constrained because nature has functional, histori$\underline{\text { cal, and evolutionary limits. Nature has a range of }}$ ways to be, but there is a limit to those ways, and
Box 6. Exotic species in Lake Michigan. The food web of Lake Michigan has been completely reconfigured by exotic species invasions, fishing, and stocking of sport fishes. Overharvest and the parasitic sea lamprey contributed to the collapse of lake charr and native coregonine populations shortly after World War II (Christie 1974). Exotic zooplanktivores, especially alewife, irrupted while the lake's populations of large piscivorous fishes were low. Chemical control of the sea lamprey was followed by highly successful stocking of exotic salmonids, leading to establishment of a sport fishery valued in excess of a billion dollars per year. Now the lake's keystone species are exotic fish whose dynamics are determined by stock and harvest. Unlike naturally reproducing fish populations, their reproduction is uncoupled from their forage base. Substantial variability in the forage base and lower trophic levels is attributed to predation by stocked fish (Kitchell and Crowder 1986). The ecosystem appears to be highly unstable and vulnerable to further invasion (National Research Council 1992b).

Residual native species may prove crucial for stabilizing fish production in the Great Lakes. In Lake Michigan, heavy stocking of salmonids has been followed by severe declines of alewife but compensatory increases in populations of native planktivorous fish. The resurgence of native planktivores has stabilized the forage base and the fishery. In Lake Ontario, trajectories of salmonids and alewife appear to be following those of Lake Michigan, but native bloaters are a minor component of the food web and may be incapable of preventing the collapse of the salmonid fishery if the alewife forage base disappears.

Biodiversity provides options for reconfiguring lake ecosystems when the environment changes (Carpenter et al. 1995). In the Great Lakes, a diverse forage base makes the ecosystem and the salmonid fishery less vulnerable to unexpected disturbances.

therefore, human changes must be within those limits.

Over the four billion year history of the earth's biota, the earth's environment has changed dramatically. However, it is likely the earth's ecosystems rarely experienced change at the rate at which it is occurring today (save perhaps for such global catastrophes as characterized the Cretaceous-Tertiary boundary). Furthermore, many changes such as extremes of land fragmentation and certain kinds of pollution have no precedent in the earth's evolutionary history. The rapidity 
of change as well as the novel character of many human impacts present special challenges to our ability to manage ecosystem sustainability.

\section{Uncertainty, surprise, and limits to knowledge}

We still have much to learn about the behavior of ecosystems, and there are significant challenges to learning it. Three types of uncertainty arise in ecosystem management (Hilborn 1987). The first category of uncertainty includes the unknowable responses and true surprises that arise from the complex and ever-changing character of ecosystems and their responses to perturbations that are unprecedented (at least to current ecosystems). Such uncertainties cannot be eliminated or reduced, but their magnitude and relative importance can be estimated. Examples of such uncertainties include ecosystem responses to unprecedented rates of climate change, carbon dioxide enrichment, or increased ultraviolet radiation. They also include such rare events as meteor impacts, earthquakes, and volcanic eruptions. Finally, uncertainties of this type may derive from cumulative effects of multiple environmental changes, such as the accumulation of insults to aquatic and marine ecosystems that have influenced populations of migratory fishes.

The second class of uncertainties arises from a lack of ecological understanding and principles upon which dependable ecological models can be constructed. Reduction of these uncertainties is occurring and more progress is possible. However, controls and replication are often impractical in such research, and the extension of results across scales of time and space is difficult at best (cf. Levin 1993).

The category of uncertainty that can be reduced most readily is that resulting from poor data quality, sampling bias, and analytical errors. Decision-makers must work with scientists and data managers to determine an acceptable level of decision error, i.e., the probability of making an incorrect decision based on data that inaccurately estimate the true state of nature.

Scientists are obliged to tell decision-makers what is known, is not known, could be known, and should be known (Carpenter 1980). This dialogue leads to the identification and prioritization of uncertainties. Sometimes uncertainties can be reduced directly through investments in targeted research and technology. These are the simple cases; in other situations, barriers to learning are deeper. Some limits to knowledge are set by the complex, nonlinear nature of ecological systems (O’Neill et al. 1986). Other limits are set by ethical constraints to experimentation that risk human life or the existence of singular, irreplaceable ecosystems. Still other limits are set by economics. Principles of sustainability mandate that living resource harvest quotas involve a "safety factor" to account for uncertainty. If uncertainty is reduced, harvest can be increased but in some cases the value of the additional harvest is less than the cost of the research and monitoring necessary to reduce uncertainty (Walters 1986). Finally, institutional barriers to learning can limit our capacity to reduce uncertainty (Lee 1993). For example, management agencies often lack systematic plans for learning, which should include prioritized listings of identified uncertainties, methods for reducing important and tractable uncertainties, procedures for evaluating existing actions, and mechanisms for retaining new knowledge in the memory of the institution (Hilborn 1992).

Adaptive management is a process that combines democratic principles, scientific analysis, education, and institutional learning to manage resources sustainably in an environment of uncertainty (Holling 1978, Lee 1993). Clearly, ecosystem management must be adaptive. In adaptive management, science makes crucial contributions through normal scientific research and education, models, and design and analysis of unique experiments at the scale of management (Holling 1978, Walters 1986, Matson and Carpenter 1990, Kitchell 1992, Lee 1993, Peterson 1993).

\section{Humans as ECOSYSTEM COMPONENTS}

Not only is the science incomplete, the system itself is a moving target, evolving because of the impacts of management and the progressive expansion of the scale of human influences on the planet...

C. S. Holling, 1993

Ecosystem management is at least as much about managing human activities as it is about managing lands and waters. A major promise of ecosystem management is its potential to integrate human activities and conservation of nature. Can ecosystem management deliver what it promises? Can human activities and natural processes be integrated to the benefit of both? All conceptualizations of ecosystem management include humans as part of ecosystems, yet the proper role of humans in ecosystems is a topic of much debate (McDonnell and Pickett 1993).

Conventional views of humans as lords and masters, stewards, protectors, or destroyers of nature all have their limitations. At one end of the spectrum in the current debate are wilderness purists who appear to believe that all management is bad, and that the best we can do for natural ecosystems is to leave them alone. This view ignores the fact that most ecosystems have already been substantially altered by human actions and are isolated and removed from their normal ecological context. At the other extreme are those who believe that human actions generally improve nature, and that no areas should be closed to intensive human activities such as commodity extraction and motorized recreation. A scientifically defensible and comprehensive view of ecosystem management has yet to be articulated, but is certainly somewhere between these two poles.

That human demand for the goods and services will increase is certain and makes sustainable ecosystem 


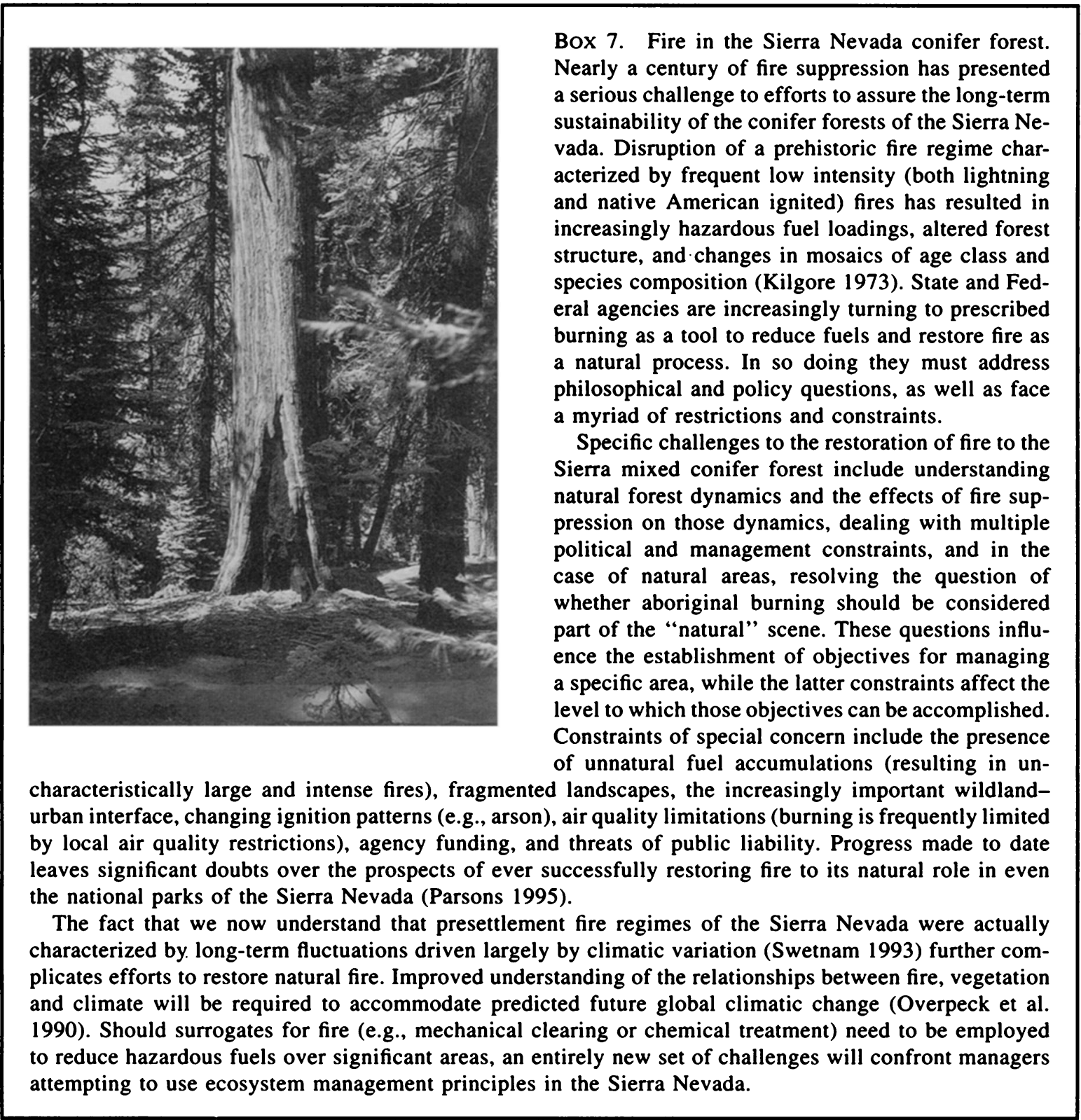

management all the more compelling and important. Over the past five decades, our numbers have grown from 2.5 to nearly 5.7 billion. Depending on assumptions upon which such predictions are based, human populations will likely reach 7-9 billion by the year 2020. The resources upon which our populations depend are delivered from ecosystems in finite quantity and the capacity for delivery of such resources is not distributed uniformly across the globe or in patterns that necessarily correlate with the areas of greatest human demand.

It is also equally certain that demands for the different kinds of goods and services provided by ecosystems will change. The "frontier," as our forebears viewed it, is gone. Two centuries ago, it was possible for our nation to disturb and deforest virtually its entire eastern half, leaving almost no trace and only a fragmentary understanding of its presettlement forests. We now understand that the management of the 19th century has left us with impoverished landscapes, and we have come to value all the more the few areas of nearpristine habitat that remain intact.

Many of our most celebrated "environmental trainwrecks" are not disputes between the "rights of nature" vs. the human demands for resources, rather they are conflicts among competing human demands. In the Pacific Northwest, so long as demand was light, forestry was not seen as competing with the commercial anadromous fishing industry. Today, those competing demands are a core issue in the development of sus- 


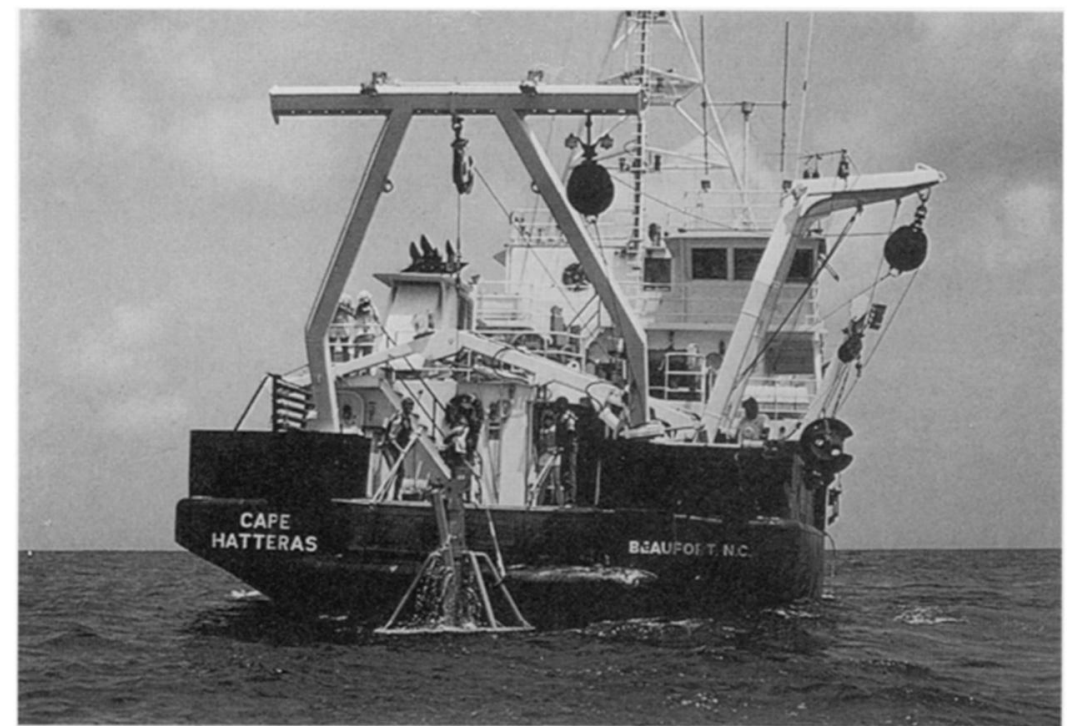

Box 8. Limits to knowledge in marine environments. The vastness and three-dimensionality of the marine environment combined with an historical lack of necessary research incentives present unique limitations on our ability to acquire knowledge in these ecosystems. For example, recent discoveries of new habitats such as deep-sea vents (Grassle 1986), cold seeps (Williams 1988), and whale carcasses (Smith et al. 1989), with attendant unique biological communities illustrate the depth of our ignorance of the range of marine habitats. Similarly, sampling of just the larger seafloor invertebrates on the continental shelfbreak only $\approx 50-80 \mathrm{~km}$ off the mid-Atlantic coast revealed 1202 species, 520 of which were new to science (Blake et al. 1987). The presence of abundant small species of phytoplankters in the oceans, the picoplankton, has only been known since 1979 (Waterbury et al. 1979). Genetic analysis has only recently revealed that certain species of importance to human society (notably the pollution indicator, Capitella capitata: Grassle and Grassle 1976; the universal biomonitor of water-column pollution, Mytilus edulis: McDonald et al. 1992; and certain corals and other reef invertebrates: Knowlton et al. 1992) are actually complexes of multiple species. Within-species genetic diversity is virtually undescribed for marine organisms (see Alberte et al. 1993).

tainable management strategies for Pacific Northwest forests.

The mismatch between the spatial and temporal scales at which humans make resource management decisions and the scales at which ecosystem processes operate present the most significant challenge to ecosystem management. Boundaries between ownerships and jurisdictions rarely match the domain of ecosystem processes. Such mismatches are often at the basis of human conflict. For example, rivers more than any other natural feature form the borders between counties, states, and countries, and thus invite conflict over the management of resources dependent on water-driven ecosystem processes.

Such resource disputes demonstrate the limitations of human institutions to achieve consensus regarding the setting and achieving of resource management goals and objectives across increasingly large scales of time and space. Few would deny concerns over such regional resources as the forests of the Pacific Northwest or the North Atlantic fishery. However, we have identified few mechanisms to translate the actions occurring within individual forest ownerships or local fishing communities into strategies to reconcile competing demands for resources or promote a regional vision for sustainability.

To say that ecosystem management is about managing human activities is not necessarily to call for increased regulation or "command and control." A rich array of policy options exists to pursue these goals. Concerns such as the rights of private property owners and local loss of jobs are not likely to diminish and ecosystem management must include strategies that deal positively with those concerns.

\section{Humans and naturalness}

"Natural" is one of the most ambiguous terms in our language, yet persists in usage because it signifies something of great esthetic and spiritual importance to many people. Although naturalness is often assumed 
to be unmeasurable, Anderson (1991) offered three criteria for assessing the relative naturalness of any area: (1) the amount of cultural energy required to maintain the system in its present state; (2) the extent to which the system would change if humans were removed from the scene; and ( 3 ) the proportion of the fauna and flora composed of native vs. non-native species. For example, a natural forest ecosystem that is self-maintaining changes little (barring stand-replacing disturbance) if left alone, and is composed of native species, is more natural than a tree farm.

A strict dichotomy of natural vs. unnatural breaks down when humans are considered part of an ecosystem. The Darwinian revolution united humans and nature in the most fundamental way-by origin. However, human cultural evolution has led to behaviors and artifacts that are qualitatively distinct from the rest of nature. The "everything is natural" view is just as dangerous in natural resources management as it is in human social behavior. Behaviors that are quite natural and that contribute to individual fitness may nevertheless be destructive in society or in natural ecosystems.

Natural is a relative rather than absolute concept. Small "natural areas" in a sea of development are heavily affected by their surroundings (Burgess and Sharpe 1981, Noss 1983) with edge effects known to penetrate great distances from their boundaries (Wilcove et al. 1986). Even the largest and most remote wilderness areas are not immune to effects of industrial civilization such as global warming, stratospheric ozone depletion, and long-distance transport of pollutants. Thus, no purely natural areas exist anywhere. Yet few would disagree that a remnant of virgin forest or tallgrass prairie is more natural than a clearcut or a shopping mall.

Natural areas, even if less than pristine, have a critical role to play in society and in ecosystem management. One of the greatest potential values of natural areas is as benchmarks or control areas for management experiments. This value was recognized by Aldo Leopold $(1941,1949)$, who pointed out that wilderness provides a "base-datum of normality" for a "science of land health." Scientists shudder to think of experiments without controls, but this is the case for much of current natural resource management (Noss 1991). Existing natural areas are imperfect baselines for many reasons, but they are the best we have. Ecosystem management, because it is essentially experimental and adaptive, requires natural areas as controls. The importance of ecosystem representation as a conservation goal, as well as the concept of endangered ecosystems, is discussed in Appendix 2.

Thus, the naturalness idea remains useful but is in need of significant revision if it is to contribute to enlightened ecosystem management. In many situations the term "historic" can be substituted for "natural" to describe the condition of a landscape before substantial alteration by human activity. Many agencies have goals
Box 9. Human impacts are ubiquitous and complex: the Bering Sea ecosystem. The Bering Sea is one of the world's most biologically productive marine regions. Most noteworthy are its many species of large marine mammals, its variety of seabirds, and its diversity of fish and shellfish. The Bering Sea ecosystem includes 450 species of fish, crustaceans, and mollusks, of which 50 species are commercially important. These fish and shellfish are a food source for millions of seabirds and at least 25 species of marine mammals

These biological resources are the foundation of the subsistence economy and culture of the indigenous peoples inhabiting the margins of the Bering Sea, and their cultural integrity is dependent upon the continued availability of these resources. Commercial interests from the United States, as well as from Russia, Japan, Poland, Korea, Taiwan, and China have also exploited these resources during the past $200 \mathrm{yr}$, taking a variety of species including fur seals, whales, sea otter, salmon, crab, shrimp, halibut, cod, herring, sole, flounder, rockfish, sablefish, and walleye pollock. Marine mammals are no longer harvested commercially, but production of fish and shellfish from the Bering Sea contributes at least $5 \%$ of the world's fishery production. Except for salmon, which have supported a commercial fishery since the turn of the century, the commercial utilization of the fish and shellfish resources of the Bering Sea began about 1950. In the early years of fishery development, stocks were aggressively harvested with little regard for sustainable use. By the mid-1970s, rockfish (most significantly Pacific Ocean Perch) and halibut stocks had been severely reduced. King crab populations and fisheries collapsed in the late 1970s. The 1980s saw a complete shift in the exploitation of the valuable groundfish resources of the U.S. Exclusive Economic Zone from predominantly foreign to exclusively domestic.

Recent declines in the populations of some Bering Sea marine mammals and seabirds have raised questions concerning the impact of present fisheries management on these fish-eating species. For instance, Stellar sea lions have declined by $50-80 \%$ in the last two decades and are now classified as "threatened" under the Endangered Species Act. The population of harbor seals may be only $15 \%$ of its 1970 s level. Bering Sea populations of pelagic seabirds such as murres and kittiwakes are also exhibiting significant declines. Some contend that these declines are due to a lack of food caused by overfishing of walleye pollock upon which these marine mammals and seabirds depend. Others believe that these changes are due to other factors, including natural cycles in productivity mediated by climate, entanglement in abandoned nets and other debris, shooting by fishermen, pollution, and disease. 
to reconstruct landscapes to some historical condition (say, as described by an early naturalist such as William Bartram) or alternately to simulate a natural or historic condition or process with current management. Restoration projects rely on historical models of some type. However, for ecosystem management it is important to recognize that any point in time is a single frame in a very long movie. Returning to a specified historic condition may not be possible; rather, a more sensible goal may be to restore natural disturbance regimes, hydrology, and other ecological processes (Noss 1985) that maintain biological elements of interest. Reconstructions of presettlement vegetation or studies of remaining natural areas in the region are essential for restoration projects based either on pattern- or process-oriented goals.

Given the dependency of heavily managed ecosystems on subsidies from less intensively managed systems, protection of natural areas in reserves is an essential component of an overall ecosystem management plan. A broad range of experimental treatments and corresponding control areas will be needed to answer many of the most important scientific questions related to ecosystem management.

The goal of preserving an area in its "natural" state presents significant challenges to the process of ecosystem management. The long and ubiquitous influence of human activities has both muddled our ability to define what is natural and greatly complicated the task of restoring and maintaining natural ecosystems. The combination of human-caused impacts (e.g., air pollution, fire suppression, introduction of alien species, or habitat fragmentation) and natural environmental change has altered ecological systems to the point that the composition, structure, and processes characterizing the "naturalness" of the area must often be first restored (White and Bratton 1980, Jordan et al. 1987). In many cases the best we can hope for is an approximation of naturalness that minimizes the influences of human activities.

\section{SCIENCE AS A MOdEL FOR ECOSYSTEM MANAGEMENT}

The greatest triumph of a scientist is the crucial experiment that shatters certainties of the past and opens up new pastures of ignorance...

William D. Ruckelshaus

What do you mean you don't know how many acid lakes there are? William D. Ruckelshaus

The acknowledgment of uncertainty is the basis for adaptive management (Holling 1978, Walters 1986, Lee 1993). Given that we still have much to learn about the behavior of ecosystems, science is, in fact, the most appropriate model for the adaptive management of ecosystems.

At root, science is little more than honest questionasking that considers all knowledge provisional and open to discussion. Hypotheses based on specific expectations derived from models of how the world works are tested by observations or experiments that acknowledge the limitations of bias and precision. In some cases our models of how the world works are refined or reinforced; in others they are proven to be inadequate and are replaced.

Managers, as well as those they serve, must accept that knowledge and modes of understanding related to ecosystem function and best management practice are provisional and subject to change with new information. In this context, management goals, protocols, and directives should be viewed as hypotheses of ways to achieve clearly stated operational goals. Monitoring programs then represent specialized kinds of research programs designed to test the hypothesis that current management will achieve the desired goals (Peterson 1993).

\section{Goals and expectations}

Often, the overarching goal in management is the sustained provision of many goods and services. For example, goals for a large forested ecosystem might include fiber production, water provision or control, hunting and fishing, recreation, and preservation of biological diversity. As a prerequisite for adaptive management, such broadly stated goals must be translated into specific operational objectives and expectations. The phrase "desired future condition" has been widely used in literature as a euphemism for such operational objectives, although, given the dynamic character of ecosystems, "desired future behavior" might better capture the objectives. Thus, to determine whether management activities are leading toward desired goals in our hypothetical forest ecosystem, expectations might be expressed in terms of forest productivity or age-class distribution, water flows, wildlife population sizes, human visitation, and status of rare and endangered species, respectively. It is essential that such expectations be stated in terms that relate to specific measurements that can be incorporated into monitoring programs.

Objectives and expectations should not be stated solely in terms of the management activities themselves. For example, where a natural disturbance must be simulated such as with prescribed fire, the management program should not have as its sole goal the reintroduction or maintenance of disturbance in the ecosystem. Rather, the implementation of a prescribed fire program should lead to specific expectations with respect to key ecosystem properties and processes such as biological diversity, nutrient availability, species recruitment, etc. (Christensen et al. 1989).

\section{Models}

Knowing exactly what to expect from complex systems is a nontrivial challenge, and models are essential to meeting this challenge. Models may take the form 
of simple compartment diagrams that provide a means of organizing information or expressing connections and relationships, or they may be developed as complex computer simulations that allow us to depict processes operating through time and across landscapes.

It is not possible to design monitoring programs to measure the dynamics of every species and ecosystem process. Models can be useful in identifying particularly sensitive ecosystem components or in setting brackets around expectations for the behavior of particular processes. They can be especially useful in identifying indices and indicators that provide a measure of the behavior of a broad suite of ecosystem properties. Finally, models often provide useful tools for exploring alternative courses of action (Lee 1993).

Modeling is often criticized because of its blatant attempt to simplify the complexity inherent in ecosystems, but that is indeed its virtue. Lee (1993) characterized models as "indispensable and always wrong." He goes on to say,

predictions of [ecosystem] behavior are . . . incomplete and often incorrect. These facts do not decrease the value of models, but they do make it clear that ecosystem models are not at all like engineering models of bridges or oil refineries. Models of natural systems are rarely that precise or reliable. Their usefulness comes from their ability to pursue the assumptions made by humans-assumptions with qualitative implications that human perception cannot always detect.

\section{Monitoring}

Monitoring refers here to data gathering and analysis focused on management expectations and designed to test the success and efficacy of management actions. Within the framework of ecosystem management, monitoring programs should be designed to determine whether management actions are moving the ecosystem toward desired future conditions and trajectories, i.e., toward goals and expectations.

Monitoring programs should be based on accepted rigorous statistical sampling designs and pay particular attention to issues of precision and bias in data gathering. Nevertheless, true replication of measurements is often impossible and in some cases sample sizes are necessarily small. Bias in data gathering is often unavoidable owing to patterns of ownership, accessibility of areas, or limited sampling techniques. These limitations are not an excuse not to establish monitoring programs, but they should be reflected in any conclusions regarding the effectiveness of management actions (Holling 1978, Walters 1986).

The design, development, and maintenance of monitoring programs requires commitment and long-term vision. In the short term, such programs represent an additional cost and are particularly hard to maintain where personnel are not necessarily permanent. In some cases, necessary measurements can be quite costly. However, it is also true that monitoring can provide a basis for understanding the costs of particular management interventions. The scientific community has much to contribute to the development of programs that will maximize information return relevant to specific management goals while minimizing costs.

We do not currently have adequate monitoring programs to assess regional ecological conditions. The Environmental Protection Agency's (EPA) Environmental Monitoring and Assessment Program (EMAP), United States Geological Survey's (USGS) National Stream Quality Accounting Network (NASQAN), and the National Oceanic and Atmospheric Administration's (NOAA) Coast Watch are aimed in the right direction. However, the overall lack of consistent support for long-term monitoring will continue to hinder progressive ecosystem management.

A decision to continue, modify, or abandon a management strategy is conditioned by perceptions of the magnitude of consequences if we are wrong, as well as value systems associated with those consequences. Within the framework of ecosystem management, we must focus on decisions that present the greatest risk to long-term sustainability.

\section{Data management and timely feedback}

Enormous amounts of ecosystem data are gathered by a wide variety of private and public resource managers, but complaints of inaccessibility and incompatibility are common. Standards for data gathering are better developed in some areas (e.g., hydrology and climate) and nonexistent in others (e.g., biological diversity). Furthermore, it is too often the case that budget limitations, institutional structures, or personnel changes result in the loss of valuable information.

Advances in computer networking and information storage now provide the means to organize, access, and distribute large quantities of data. Institutional structures should guarantee that such information is fed back to managers in a timely fashion and in a form that is directly relevant and accessible to their management activities.

\section{Research}

There is much that we do not know or understand about the structure and functioning of ecosystems. Feedback from adaptive management will certainly reduce our level of ignorance, but research focused on a more detailed understanding of ecosystem processes is critical. Research programs driven solely by the immediate needs of management risk overlooking new insights and opportunities. However, programs that are innocent of an understanding of public concerns and priorities risk being irrelevant.

Scientists should not labor under the illusion that management is limited simply by the supply of data or that communication is a unilateral problem of infor- 
mation flow to managers. There is a large array of potentially interesting problems that the research community might wish to tackle, but only a considerably smaller subset of that array is relevant to compelling management questions. Open lines of communication between managers and researchers are critical to the setting of priorities for specific research needs.

\section{Education}

There is clearly a need for additional education if successful adaptive management systems are to be developed. Managers have much to learn with regard to the setting of goals and expectations, monitoring, and data handling, and scientists require greater understanding of the priorities of and challenges to ecosystem managers. However, public education is critical. The limited public understanding of how science is done, much less the nuances of specific scientific issues, present special challenges to adaptive management. Public expectations of both managers and scientists are often unrealistically high, a situation that is sometimes fostered by actions and statements of managers and scientists. It will be unlikely that society will accept "science as a model for ecosystem management" in the absence of a clearer understanding of the importance of uncertainty to both science and management.

\section{IMPLEMENTING ECOSYSTEM MANAGEMENT}

Clearly, ecosystem management requires application of ecological science to natural resource actions. Moving from concepts to practice is a daunting challenge and will certainly require the following steps and actions.

\section{Defining sustainable goals and objectives}

Critics argue that ecosystem management is little more than a collection of strategies aimed at reducing extractive use of natural resources and preserving natural ecosystems. Although maintaining biological diversity and establishment of wilderness preserves may be important strategies in an ecosystem management plan, and in some areas maintenance of natural systems may be a central goal, ecosystem management should be seen as the collection of protocols and actions that allow us to deliver the essential goods and services of ecosystems in perpetuity. Ecosystem management does not deny the need or wish to harvest fiber from our forests, fish from our coastal waters or lakes, or energy from rivers and streams. It simply confronts the reality that in order to meet these needs or wants sustainably, we must value our ecosystems for more than just economically important goods and services. Given the reality of human population growth and increasing demands for ecosystem goods and services, the issue of sustainable management is especially compelling.

Only a small minority would consciously advocate policies or activities that would diminish the capacity of ecosystems to provide, at levels that we enjoy today, goods and services to future generations. Indeed, sustained capacity and potential are legally mandated requirements for most public agencies charged with the stewardship of natural resources. What we have learned is that, however good our intentions, management that focuses on commodity resources alone, that does not acknowledge the importance of diversity and complexity, that is not aware of influences of and impacts on surrounding areas, and that concerns itself with short time frames, is not likely to be sustainable in the long term.

Sustainable strategies for the provision of ecosystem goods and services cannot take as their starting points statements of need or want such as mandated timber supply, water demand, or arbitrarily set harvests of shrimp or fish. Rather, sustainability must be the primary objective, and levels of commodity and amenity provision adjusted to meet that goal.

\section{Reconciling spatial scales}

Implementation of ecosystem management would be greatly simplified if the spatial scales and borders of management jurisdictions were congruent with the behavior of processes central to sustained ecosystem functioning. This is rarely the case for ecological processes, and, given the variation in spatial domain among processes, a perfect fit for all processes simultaneously is virtually impossible. Thus, reconciliation of objectives and actions of the various stakeholders within the domain of an ecosystem must be a central element in implementation of sustainable management strategies. "Because ecosystems exist at several geographic scales, so, too, should efforts to coordinate activities that affect them" (Government Accounting Office 1994).

In some cases, stakeholders may be identified by simply matching maps of ownership with the appropriate ecosystem boundaries, such as the domain of a watershed. More often, stakeholders also include parties who have no title or legal jurisdiction, but are dependent on or have an interest in the goods and services provided by an ecosystem. For example, communities dependent on clean water delivered from a watershed are obvious stakeholders in the management of that watershed. In other situations, such as the management of old-growth forests in the Pacific Northwest or populations of marine mammals in coastal waters, the network of stakeholders is very complex. People who may never visit a Douglas-fir-hemlock forest or see a humpback whale nevertheless have strong commitments to their conservation as evidenced by a willingness to support nongovernmental organizations focused on these issues. They too are undeniably stakeholders.

This committee was not charged with exploring the intricacies of strategies for identifying stakeholders and reconciling conflicts among their interests and objec- 
tives. Nevertheless, we do recognize this as one of the greatest challenges to implementation of ecosystem management, and that the success of any ecosystem management plan depends on the identification and involvement of stakeholders "up front" in the planning process. There is a growing literature on the theory and practice of conflict resolution (see, for example, Lee 1993) and a growing number of case studies where ecosystem management strategies have been implemented despite complex patterns of jurisdiction and a multiplicity of competing interests (Box 10).

\section{Reconciling temporal scales}

Ecosystem management must deal with time scales that transcend human lifetimes and almost certainly exceed the timelines for other political, social and economic agendas. Public and private management agencies are often forced to make fiscal year decisions about resources whose behavior is better measured in centuries. Given sufficient time and space, unexpected events are certain to happen; however, managers are rarely prepared for such surprises.

To implement ecosystem management, we must develop strategies that incorporate long-term planning and commitment, while recognizing the need to make short-term decisions. Ecosystem management is not an antidote for surprise; rather, it is an approach to management that acknowledges that unlikely events do happen (Holling 1993).

\section{Making the system adaptable and accountable}

Successful ecosystem management depends on institutions that are adaptable to variations and changes in ecosystem characteristics, as well as to changes in our knowledge base. Ecosystem managers must acknowledge ignorance and uncertainty, and adaptive management must be an integral component of ecosystem management implementation. As indicated above, managers must recognize that knowledge and understanding are provisional and see their activities as experimental.

To argue that management should be viewed as experimental is not to advocate capricious implementation of untried or avante garde actions. It is rather to acknowledge the limits of our understanding of the consequences of even conventional management procedures to the complex array of ecosystem components and processes necessary for sustained function. Lee (1993) outlines a number of institutional conditions that affect the implementation of experimental approaches to management. Decision-makers must be committed to improving outcomes over biological time scales, be aware of the experimental nature of management, and be willing to accept the risk of perceived failures. To do this, managers and decision-makers must have the understanding of stakeholders and a mandate for action in the face of uncertainty. Managers who profess certain knowledge engender like expec-
Box 10. Ecosystem management of the Great Barrier Reef, Australia. Coral reef ecosystems have long been treasured by both ecologists and the general public for their biodiversity, complexity, and beauty (Darwin 1842, Connell 1978). The primary economic value of these ecosystems has traditionally been the opportunities they afford for observation and recreation. However, in recent years, increased consumptive uses of coral reef ecosystems and various polluting activities on land have created the potential for destroying their integrity and diminishing the services they provide. The Great Barrier Reef Marine Park Authority has developed a model ecosystem management plan to protect one of the world's most diverse coral reefs (Kelleher and Kenchington 1992).

The Great Barrier Reef Marine Park is not a National Park, but rather a protected area managed for multiple uses, with integrated oversight by the Great Barrier Reef Marine Park Authority (GBRMPA). Zoning is the tool used to allow, yet separate, conflicting usages. A few activities such as oil and gas exploration, minerals mining, littering, spearfishing by scuba, and taking of some larger fishes, are prohibited throughout the Park. Three main zones are identified: (1) preservation zones, where only strictly controlled scientific research is allowed; (2) marine national park zones, where permitted uses are scientific, educational, and recreational; and (3) general-use zones, where various uses are permitted including recreational and commercial fishing using practices compatible with the maintenance of ecosystem integrity. In addition, smaller, specialuse zones are designated to protect critical breeding or nesting sites, or to provide important protection for natural areas or research. To cope with increases in ecotourism on the reef a special tourist strategy has been adopted to allow viewing of the natural reef free of the impacts of fishing, but restricting floating structures to specific areas.

Ecologically sustainable utilization is the core principle of the GBRMPA. Public involvement and education are critical to this ecosystem management plan which emphasizes public accountability, efficiency of operation, minimization of regulation, adaptability to changing circumstances, and scientific credibility. Preservation zones provide the "touchstone" for evaluation of patterns of change in overall ecosystem behavior. 
tations from the public and justified condemnation when policies fail or actions result in surprises.

Changes in organizational cultures and commitments will be critical to the implementation of adaptive management (Lee 1993). Resources must be sufficient to implement appropriate monitoring systems, some of which may require measurements at very large scales. Furthermore, there must be sufficient institutional stability and sustained commitment to measure long-term outcomes. Monitoring and research programs are likely to add significant costs to management in many cases and their added value may not be realized in the short term.

Institutional cultures must encourage learning from experience and research. Enhanced communication among scientists, managers, and decision makers is essential. There is a clear need for partnerships between the scientific and management communities (Likens 1992).

\section{The role of scientists in ecosystem management}

"Science as a model for ecosystem management" is unlikely to become reality unless scientists are involved with managers and the public in adaptive management processes. Clearly ecological science is critical to the development and refinement of models necessary for effective management. But, this is not simply a matter of unilateral information flow-scientists telling managers what is important. Although management is starved for information, its needs are often quite particular. Communication must flow in both directions and become an iterative dialogue, and the scientific community must understand what pieces of information are critical and be willing to prioritize its research accordingly.

Scientists have much to offer in the development of monitoring programs. They can assist in the development of sampling approaches and statistical analyses that will increase precision and minimize bias. Models can help in the identification of key indices of ecosystem functioning that can reduce monitoring costs. Scientists have much to gain from assisting in this area. Although monitoring efforts may not be designed to address basic research questions, it is the case that such data sets have provided a wellspring of long-term information to research.

Delivering a refereed journal publication to a manager's desk is not sufficient if we wish our best science to move quickly into management application. We must develop improved means to communicate effectively and clearly the results of management experiments, as well as basic research. This will call for more professionals with an understanding of the scientific, management, and social issues, and the ability to communicate with scientists, managers, and the public. The need for adaptive management is certainly a persuasive argument for a continuous training philosophy aimed at achieving effective dialogue between managers and researchers as our needs and knowledge base change.

\section{EPILOGUE}

Lore to the contrary, it might be argued that natural resource management was in fact the first of human professions. The successes and failures of human societies on this planet have been and will continue to be inextricably linked to cycles of resource use and ecological change.

If the creator were a corporate manager, he or she might well pose the question, "has human management added value to the earth?" From a purely human perspective, the reply would likely be an emphatic yes. After all, there are now 5.5 billion of us.

But, any corporate manager knows that, when inventories are depleted and the physical plant is allowed to deteriorate, it is possible to make money in the short term while watching your net worth waste away. Such is the road to bankruptcy. Businesses routinely make decisions with short-term costs, but obvious benefits to their long-term sustainability.

This metaphor captures the sense of intergenerational equity and the stewardship responsibilities that are central to an ecosystem management philosophy. Ecosystem management is the ecological analog to the economic stewardship of a trust or endowment dedicated to benefit all generations.

Ecosystem management is not a rejection of the anthropocentric for a totally biocentric world view. Rather, it is management that acknowledges the importance of humans needs while at the same time confronting the reality that the capacity of our world to meet those needs in perpetuity has limits and depends on the functioning of ecosystems.

\section{ACKNOWLEDGMENTS}

The committee expresses its gratitude to Drs. Richard Carpenter, C. S. Holling, Gene Likens, Jane Lubchenco, Judy Meyer, Robert Naiman, Robert Peet, and Fred Swanson for comments on and reviews of this manuscript. Input to the chair from many members of the Ecological Society of America is acknowledged with sincere thanks.

\section{LiTERATURE Cited}

Agee, J., and D. Johnson. 1988. Ecosystem management for parks and wilderness. University of Washington Press, Seattle, Washington, USA.

Alberte, R. S., G. Suba, G. Procaccini, R. C. Zimmerman, and S. R. Fain. 1993. Assessment of genetic diversity of seagrass populations using DNA fingerprinting: implications for population stability and management. Proceedings of the National Academy of Sciences (USA), in press.

Allen, T. F. H., and T. B. Starr. 1982. Hierarchy. University of Chicago Press, Chicago, Illinois, USA.

American Forest and Paper Association. 1993. Sustainable forestry principles and implementation guidelines. American Forest and Paper Association, Washington, D.C., USA.

Anderson, J. 1991. A conceptual framework for quantifying naturalness. Conservation Biology 5:348.

Antonovics, J. 1968. Evolution in closely adjacent plant populations. Heredity 23:219-238. 
Aron, W., D. Fluharty, D. McCaughran, and J. F. Ross. 1993. Fisheries management. Science 261:813-814.

Baker, W. L. 1989a. Landscape ecology and nature reserve design in the Boundary Waters Canoe Area, Minnesota. Ecology 70:23-35.

- 1989b. Effect of scale and spatial heterogeneity on fire-interval distributions. Canadian Journal of Forest Research 19:700-706.

Bateson, G. 1972. Steps to an ecology of mind. Ballantine Books, New York, New York, USA.

Blake, J. A., B. Hecker, J. F. Grassle, B. Brown, M. Wade, P. D. Boehm, E. Baptiste, B. Hilbig, N. Maciolek, R. Petrecca, R. E. Ruff, V. Starczak, and L. Watling. 1987. Study of biological processes on the U.S. South Atlantic slope and rise. Phase 2. Final Report. Prepared for the U.S. Department of the Interior, Minerals Management Service, Washington, D.C., USA. OCS Study MMS 860096.

Bormann, F. H., and G. E. Likens. 1979. Pattern and process in a forested ecosystem. Springer Verlag, New York, New York, USA.

Botkin, D. B. 1990. Discordant harmonies. Oxford University Press, New York, New York, USA.

Botkin, D. B., and M. J. Sobel. 1975. Stability in timevarying ecosystems. American Naturalist 109:625-646.

Bottom, D. L., K. K. Jones, J. D. Rodgers, and R. F. Brown. In press. Research and management in the northern California Current ecosystem. In K. Sherman, L. Alexander, and B. Gold, editors. Stress, mitigation, and sustainability of large marine ecosystems. American Association for the Advancement of Science, Washington, D.C., USA

Bourgeron, P. S., and L. Engelking, editors. 1992. Preliminary compilation of a series level classification of the vegetation of the western United States using a physiognomic framework. Report to the Idaho Cooperative Fish and Wildlife Research Unit. Western Heritage Task Force, Nature Conservancy, Boulder, Colorado, USA.

Burgess, R. L., and D. M. Sharpe. 1981. Forest island dynamics in man-dominated landscapes. Springer-Verlag, New York, New York, USA.

Capra, F. 1975. The tao of physics. Shambhala, Boston, Massachusetts, USA.

. 1988. Uncommon wisdom. Shambhala, Boston, Massachusetts, USA.

Carlton, J. T. 1985. Transoceanic and interoceanic dispersal of coastal marine organisms: the biology of ballast water. Oceanography and Marine Biology Annual Review 23 313-371.

1989. Man's role in changing the face of the ocean: biological invasions and implications for conservation of near-shore environments. Conservation Biology 3:265273.

Carpenter, R. A. 1980. Using ecological knowledge for development planning. Environmental Management 4:13-20.

Carpenter, S. R. 1990. Large-scale perturbations: opportunities for innovation. Ecology 71:2038-2043.

Carpenter, S. R., T. M. Frost, L. Persson, M. Power, and D. Soto. 1995. Freshwater ecosystems: linkages of complexity and processes. Chapter 12 in $\mathrm{H}$. Mooney et al., editors. Functional roles of biodiversity: a global perspective. John Wiley \& Sons, New York, New York, USA.

Carpenter, S. R., and J. F. Kitchell, editors. 1993. The trophic cascade in lakes. Cambridge University Press, London, England.

Christensen, N. L., et al. 1989. Interpreting the Yellowstone fires of 1988. BioScience 39:678-685.

Christie, W. J. 1974. Changes in the fish species composition of the Great Lakes. Journal of the Fisheries Research Board of Canada 31:827-854.

Clements, F. E. 1916. Plant succession: an analysis of the development of vegetation. Carnegie Institution, Washington, D.C., USA.

Congressional Research Service. 1994. Ecosystem management: federal agency activities. Congressional Research Service, Library of Congress, Washington, D.C., USA.

Connell, J. H. 1978. Diversity in tropical rain forests and coral reefs. Science 199:1302-1310.

Connell, J. H., and R. O. Slatyer. 1977. Mechanisms of succession in natural communities and their role in community stability and organization. American Naturalist 111:11191144.

Connell, J. H., and W. P. Sousa. 1983. On the evidence needed to judge ecological stability or persistence. American Naturalist 121:789-824.

Cowles, H. C. 1899. The ecological relationships of the vegetation on the sand dunes of Lake Michigan. Botanical Gazette 27:95-391.

Darwin, C. 1842. The structure and distribution of coral reefs. Smith, Elder \& Company, London, England.

Davis, M. B. 1981. Quaternary history and the stability of forest communities. Pages 132-153 in D. C. West, H. H. Shugart, and D. B. Botkin, editors. Forest succession. Springer-Verlag, New York, New York, USA.

DeAngelis, D. L., and J. C. Waterhouse. 1987. Equilibrium and nonequilibrium concepts in ecological models. Ecological Monographs 57:1-21.

Delcourt, H. R., and P. A. Delcourt. 1991. Quaternary ecology. Chapman and Hall, New York, New York, USA.

Dunn, C. P., D. M. Sharpe, G. R. Guntenspergen, F. Stearns, and Z. Yang. 1991. Methods for analyzing temporal changes in landscape pattern. Pages 173-198 in M. G. Turner and R. H. Gardner, editors. Quantitative methods in landscape ecology. Springer-Verlag, New York, New York, USA.

Eastside Forest Health Assessment Team. 1993. Eastside Forest Ecosystem Health Assessment: Volume 1, Executive Summary. United States Department of Agriculture Forest Service, Washington, D.C., USA.

Egerton, F. N. 1973. Changing concepts of the balance of nature. Quarterly Review of Biology 48:322-350.

Ehrlich, A. H., and P. R. Ehrlich. 1986. Needed: an endangered humanity act? Amicus Journal. Reprinted on pages 298-302 of K. A. Kohm, editor. 1991. Balancing on the brink of extinction: the endangered species act and lessons for the future. Island Press, Washington, D.C., USA.

Ehrlich, P. R., and A. H. Ehrlich. 1991. Healing the planet: strategies for resolving the environmental crisis. AddisonWesley, Reading, Massachusetts, USA.

Forbes, S. A. 1887. The lake as a microcosm. Bulletin of the Peoria Scientific Association. Illinois Natural History Survey Bulletin 15:537-550.

Forest Ecosystem Management Team (FEMAT). 1993. Forest ecosystem management: an ecological, economic, and social assessment. Joint publication of the United States Department of Agriculture: Forest Service; United States Department of Commerce: National Oceanic and Atmospheric Administration and National Marine Fisheries Service; United States Department of Interior: Bureau of Land Management, Fish and Wildlife Service, and National Park Service; and United States Environmental Protection Agency, Washington, D.C., USA.

Foster, D. R. 1988. Disturbance history, community organization and vegetation dynamics of the old-growth Pisgah Forest, southwestern New Hampshire, USA. Journal of Ecology 76:105-134.

Franklin, J. F. 1993. Lessons from old-growth. Journal of Forestry 91:10-13.

- 1996. Ecosystem management: an overview. In $\mathrm{S}$. Haney and M. Boyce, editors. Ecosystem management: ap- 
plications for sustainable forest and wildlife resources. Yale University Press, New Haven, Connecticut, USA, in press.

Golley, F. B. 1993. A history of the ecosystem concept in ecology. Yale University Press, New Haven, Connecticut, USA.

Government Accounting Office. 1994. Ecosystem management: additional actions needed to adequately test a promising approach. United States General Accounting Office Report to Congressional Requesters GAO/RCED-94-111.

Graham, R. W. 1986. Response of mammalian communities to environmental changes during the Late Quaternary. Pages 300-313 in J. Diamond and T. J. Case, editors. Community ecology. Harper \& Row, New York, New York, USA.

Grassle, J. F. 1986. The ecology of deep-sea hydrothermal vent communities. Advances in Marine Biology 23:301362 .

Grassle, J. P., and J. F. Grassle. 1976. Sibling species in the marine pollution indicator Capitella (Polychaeta). Science 192:567-569.

Grumbine, R. E. 1994. What is ecosystem management? Conservation Biology 8:27-38.

Gulati, R. D., E. H. R. R. Lammens, M. L. Meijer, and E. van Donk, editors. 1990. Biomanipulation-tool for water management. Kluwer Academic, Dordrecht, The Netherlands.

Hagen, J. B. 1992. An entangled bank: the origins of ecosystem ecology. Rutgers University Press, New Brunswick, New Jersey, USA.

Hilborn, R. 1987. Living with uncertainty in resource management. North American Journal of Fisheries Management 7:1-5.

. 1992. Can fisheries agencies learn from experience? Fisheries 17:6-14.

Holland, R. F. 1987. Is Quercus lobata a rare plant? Approaches to conservation of rare plant communities that lack rare plant species. Pages 129-132 in T. S. Elias, editor. Conservation and management of rare and endangered plants. California Native Plant Society, Sacramento, California, USA.

Holling, C. S. 1978. Adaptive environmental assessment and management. John Wiley \& Sons, New York, New York, USA.

- 1993. Investing in research for sustainability. Ecological Applications 3:552-555.

- 1996. Engineering resilience vs. ecological resilience. Proceedings of the National Academy of Sciences, USA, in press.

Hunt, C. E. 1989. Creating an endangered ecosystems act. Endangered species update 6(3-4): $1-5$.

Hunter, M. L., G. L. Jacobson, and T. Webb. 1988. Paleoecology and the coarse-filter approach to maintaining biological diversity. Conservation Biology 2:375-385.

Iacobelli, T., K. Kavanagh, and S. Rowe. 1995. A protected areas gap analysis methodology: planning for conservation of biodiversity. World Wildlife Fund, Toronto, Ontario, Canada.

Iverson, L. R. 1988. Land-use changes in Illinois, USA: the influence of landscape attributes on current and historic land use. Landscape Ecology 2:45-62.

Jennings, F. 1993. Founders of America. Norton, New York, New York, USA.

Johnson, B. M., and S. R. Carpenter. 1994. Functional and numerical responses: a framework for fish-angler interactions? Ecological Applications 4:808-821.

Jones, C., and J. Lawton, editors. 1994. Linking species and ecosystems. Chapman and Hall, New York, New York, USA.

Jordan, W. R., M. E. Gilpin, and J. D. Aber, editors. 1987.
Restoration ecology. Cambridge University Press, Cambridge, England

Karlin, E. F. 1995. Population growth and the global environment: an ecological perspective. Pages 19-37 in W. J. Makofske and E. F. Karlin, editors. Technology, development and global environmental issues. HarperCollins College Publishers, New York, New York, USA.

Kelleher, G., and R. Kenchington. 1992. Guidelines for establishing marine protected areas. IUCN (The World Conservation Union), Gland, Switzerland

Kendeigh, S. C., H. I. Baldwin, V. H. Cahalane, C. H. D. Clarke, C. Cottam, I. M. Cowan, P. Dansereau, J. H. Davis, F. W. Emerson, I. T. Haig, A. Hayden, C. L. Hayward, J. M. Linsdale, J. A. MacNab, and J. E. Potzger. 1950-1951. Nature sanctuaries in the United States and Canada: a preliminary inventory. Living Wilderness 15(35):1-45.

Keystone Center. 1991. Biological diversity on federal lands. Keystone Center, Keystone, Colorado, USA

Kilgore, B. M. 1973. The ecological role of fire in Sierran conifer forests: its application to national park manage ment. Journal of Quaternary Research 3:496-513.

Kitchell, J. F., editor. 1992. Food web management: a case study of Lake Mendota. Springer-Verlag, New York, New York, USA.

Kitchell, J. F., and L. B. Crowder. 1986. Predator-prey in teractions in Lake Michigan: model predictions and recent dynamics. Environmental Biology of Fishes 16:205-211.

Knowlton, N., E. Weil, L. A. Weigt, and H. M. Guzman. 1992. Sibling species in Montastraea annularis, coral bleaching, and the coral climate record. Science 255:330333

Lee, K. N. 1993. Compass and gyroscope: integrating science and politics for the environment. Island Press, Washington, D.C., USA.

Leopold, A. 1941. Wilderness as a land laboratory. Living Wilderness 6:3.

1949. A Sand County almanac. Oxford University Press, New York, New York, USA.

Leshan, L., and H. Margenau. 1982. Einstein's space and Van Gogh's sky. Macmillan, New York, New York, USA. Levin, S. A. 1990. Physical and biological scales and the modelling of predator-prey interactions in large marine ecosystems. Chapter 14 in K. Sherman, L. M. Alexander, and B. D. Gold, editors. Large marine ecosystems: patterns, processes, and yields. American Association for the Advancement of Science, Washington, D.C., USA.

. 1992. The problem of pattern and scale in ecology. Ecology 73:1943-1967.

- 1993. Forum: science and sustainability. Ecological Applications 3:545-589.

Levin, S. A., and R. T. Paine. 1974. Disturbance, patch formation, and community structure. Proceedings of the National Academy of Sciences (USA) 71:2744-2747.

Likens, G. 1992. An ecosystem approach: its use and abuse. Excellence in ecology, book 3. Ecology Institute, Oldendorf/Luhe, Germany.

Lippke, B., and C. D. Oliver. 1993. Managing for multiple values. Journal of Forestry 91:14-18.

Lubchenco, J., A. M. Olson, L. B. Brubaker, S. R. Carpenter, M. M. Holland, S. P. Hubbell, S. A. Levin, J. A. MacMahon, P. A. Matson, J. M. Melillo, H. A. Mooney, C. H. Peterson, H. R. Pulliam, L. A. Real, P. J. Regal, and P. G. Risser. 1991. The Sustainable Biosphere Initiative: an ecological research agenda. Ecology 72:371-412.

Lubchenco, J., P. G. Risser, A. C. Janetos, J. R. Gosz, B. D. Gold, and M. M. Holland. 1993. Priorities for an environmental science agenda for the Clinton-Gore Administration: recommendations for transition planning. Bulletin of the Ecological Society of America 74:4-8.

Ludwig, D., R. Hilborn, and C. Walters. 1993. Uncertainty, 
resource exploitation, and conservation: lessons from history. Science 260:17, 36.

MacArthur, R. H., and E. O. Wilson. 1967. Island biogeography. Princeton University Press, Princeton, New Jersey, USA

Margalef, R. 1968. Perspectives in ecological theory. University of Chicago Press, Chicago, Illinois, USA.

Matson, P. A., and S. R. Carpenter, editors. 1990. Special Feature: statistical analysis of ecological response to largescale perturbations. Ecology 71:2037-2068.

May, R. M. 1973. Stability and complexity in model ecosystems. Princeton University Press, Princeton, New Jersey, USA.

Mayer, K. E., and W. F. Laudenslayer. 1988. A guide to wildlife habitats of California. California Department of Forestry and Fire Protection, Sacramento, California, USA

McDonald, J. H., R. Seed, and R. K. Koehn. 1992. Allozymes and morphometric characters of three species of $M y$ tilus in the Northern and Southern Hemispheres. Marine Biology 2:323-333.

McDonnell, M. J., and S. T. A. Pickett. 1993. Human as components of ecosystems: the ecology of subtle human effects and populated areas. Springer Verlag, New York, New York, USA.

Möbius, K. 1877. Die Auster und die Austernwirtschaft. Verlag von Wiegandt, Hempel und Parey, Berlin (translated by H. J. Rice and published in Fish and Fisheries Annual Re port of the Commission for the Year, Volume 3, Number 29, pages 681-747)

Mooney, H. A., and M. Godron, editors. 1983. Disturbance and ecosystems. Springer-Verlag, New York, New York, USA.

Myers, R. L. 1985. Fire and the dynamic relationship between Florida sandhill and sand pine scrub vegetation. Bulletin of the Torrey Botanical Club 112:241-252.

National Marine Fisheries Service (NMFS). 1991. Strategic plan of the National Marine Fisheries Service, goals and objectives. U.S. Department of Commerce, National Oceanic and Atmospheric Administration NMFS, Seattle, Washington, USA.

National Research Council. 1990. Forestry research: a man date for change. National Academy Press, Washington, D.C., USA.

1992a. Science and the National Parks. National Academy Press, Washington, D.C., USA.

. 1992b. Restoration of aquatic ecosystems. National Academy Press, Washington, D.C., USA

Norse, E. A., editor. 1993. Global marine biological diversity, a strategy for building conservation into decision making. Island Press, Washington, D.C., USA.

North Pacific Fishery Management Council (NPFMC). 1992. Stock assessment and fishery evaluation report for the groundfish resources of the Bering Sea/Aleutian Islands regions as projected for 1993. NPFMC, Anchorage, Alaska USA.

Noss, R. F. 1983. A regional approach to maintain diversity. BioScience 33:700-706.

1985. On characterizing presettlement vegetation: how and why. Natural Areas Journal 5:5-13.

. 1987. From plant communities to landscapes in conservation inventories: A look at The Nature Conservancy (USA). Biological Conservation 41:11-37.

1991. Sustainability and wilderness. Conservation Biology 5:120-122.

- 1992. The Wildlands Project: land conservation strategy. Wild Earth (Special Issue):10-25

Noss, R. F., and L. D. Harris. 1986. Nodes, networks, and MUMs: preserving diversity at all scales. Environmental Management 10:299-309.

Noss, R. F., E. T. LaRoe III, and J. M. Scott. 1995. Endan- gered ecosystems of the United States: a preliminary assessment of loss and degradation. Biological Report 28. National Biological Service, Washington, D.C., USA

Odum, E. P., and M. G. Turner. 1990. The Georgia landscape: a changing resource. Pages 137-164 in I. S. Zonneveld and R. T. T. Forman, editors. Changing landscapes: an ecological perspective. Springer-Verlag, New York, New York, USA.

O'Neill, R. V., D. L. DeAngelis, J. B. Waide, and T. F. H. Allen. 1986. A hierarchical concept of ecosystems. Princeton University Press, Princeton, New Jersey, USA.

Orians, G. H. 1993. Endangered at what level? Ecological Applications 3:206-208.

Overbay, J. C. 1992. Ecosystem management. Pages 3-15 in Taking an ecological approach to management. United States Department of Agriculture Forest Service Publication Wo-WSA-3.

Overpeck, J. T., D. Rind, and R. Goldberg. 1990. Climateinduced changes in forest disturbance and vegetation. Nature 343:51-53.

Paine, R. T. 1980. Food webs: linkage, interaction strength and community infrastructure. Journal of Animal Ecology 49:667-685.

Paine, R. T., and S. A. Levin. 1981. Intertidal landscapes: disturbance and the dynamics of pattern. Ecological Monographs 51:145-178.

Parsons, D. J. 1995. Restoring fire to the giant sequola groves: what have we learned in 25 years. Pages $256-258$ in J. K. Brown, R. W. Mutch, C. W. Spoon, and R. H. Wakimoto, editors. Proceedings of a Symposium on Fire in Wilderness and Park Management. United States Department of Agriculture Forest Service General Technical Report INT-GTR-320

Parsons, D. J., D. M. Graber, J. K. Agee, and J. W. van Wagtendonk. 1986. Natural fire management in national parks. Environmental Management 10:21-24.

Peterson, C. H. 1993. Improvement of environmental impact analysis by application of principles derived from manipulative ecology: lessons from coastal marine case histories. Australian Journal of Ecology 18:21-52.

Pickett, S. T. A., V. T. Parker, and P. L. Fiedler. 1992. The new paradigm in ecology: implications for conservation biology above the species level. Pages 65-88 in P. L. Fiedler and S. K. Jain, editors. Conservation biology: the theory and practice of nature conservation, preservation, and management. Chapman and Hall, New York, New York, USA.

Pickett, S. T. A., and P. S. White, editors. 1985. The ecology of natural disturbance and patch dynamics. Academic Press, New York, New York, USA

Richardson, C. J. 1994. Ecological functions and human values in wetlands: a framework for assessing forestry impacts. Wetlands 14:1-9.

Ricklefs, R. E. 1990. Scaling pattern and process in marine ecosystems. Chapter 13 in K. Sherman, L. M. Alexander, and B. D. Gold, editors. Large marine ecosystems: patterns, processes, and yields. American Association for the Advancement of Science, Washington, D.C., USA.

Riemann, B., and E. Hoffmann. 1991. Ecological consequences of dredging and bottom trawling in the Limfjord, Denmark. Marine Ecology Progress Series 69:171-178.

Romme, W. H. 1982. Fire and landscape diversity in subalpine forests of Yellowstone National Park. Ecological Monographs 52:199-221.

Romme, W. H., and D. G. Despain. 1989. Historical perspective on the Yellowstone fires of 1988. BioScience 39 695-699.

Romme, W. H., and D. H. Knight. 1982. Landscape diversity: the concept applied to Yellowstone Park. BioScience 32 $664-670$.

Sala, O. E., W. J. Parton, L. A. Joyce, and W. K. Lauenroth. 
1988. Primary production of the central grassland region of the United States. Ecology 69:40-45.

Savory, A. 1988. Holistic resource management. Island Press, Washington, D.C., USA.

Schindler, D. W. 1987. Detecting ecosystem response to anthropogenic stress. Canadian Journal of Fisheries and Aquatic Sciences 44(Supplement):6-25.

Scott, J. M., F. Davis, B. Csuti, R. Noss, B. Butterfield, C Groves, J. Anderson, S. Caicco, F. D'Erchia, T. C. Edwards, J. Ulliman, and R. G. Wright. 1993. Gap analysis: a geographical approach to protection of biological diversity. Wildlife Monographs 123:1-41.

Shapiro, J., V. Lamarra, and M. Lynch. 1975. Biomanipulation: an ecosystem approach to lake restoration. Pages 85-96 in P. L. Brezonik and J. L. Fox, editors. Proceedings of a Symposium on Water Quality Management Through Biological Control. University of Florida, Gainesville, Florida, USA.

Shelford, V. E., editor. 1926. Naturalist's guide to the Americas. Williams and Wilkins, Baltimore, Maryland, USA.

- 1933. Ecological Society of America: a nature sanctuary plan unanimously adopted by the Society, December 28, 1932. Ecology 14:240-245.

Sherman, K., L. M. Alexander, and B. D. Gold, editors. 1990. Large marine ecosystems: patterns, processes, and yrelds. American Association for the Advancement of Science Washington, D.C., USA

Simenstad, C. A., J. A. Estes, and K. W. Kenyon. 1978 Aleuts, sea otters and alternate stable-state communities. Science 200:403-411.

Slocombe, D. S. 1993. Implementing ecosystem-based management. BioScience 43:612-621.

Smith, C. R., H. Kukert, R. A. Wheatcroft, P. A. Jumars, and J. W. Deming. 1989. Vent fauna on whale remains. Nature 341:27-28.

Society of American Foresters. 1993. Sustaining long-term forest health and productivity. Society of American Foresters, Bethesda, Maryland, USA.

Sousa, W. P. 1979. Disturbance in intertidal boulder fields: the nonequilibrium maintenance of species diversity. Ecology 60:1225-1239.

Sprugel, D. G. 1976. Dynamic structure of wave-regenerated Abies balsamea forests in the north-eastern United States. Journal of Ecology 64:889-911.

Stanley, T. R. 1995. Ecosystem management and the arrogance of humanism. Conservation Biology 9:255-262.

Sutherland, J. P. 1974. Multiple stable points in natural communities. American Naturalist 108:859-873.
Swetnam, T. W. 1993. Fire history and climate change in giant sequoia groves. Science 262:885-889.

Tansley, A. G. 1935. The use and abuse of vegetational concepts and terms. Ecology 16:284-307.

Tilman, D., and J. A. Downing. 1994. Biodiversity and stability in grasslands. Nature 367:363-365.

Turner, M. G., editor. 1987. Landscape heterogeneity and disturbance. Springer-Verlag, New York, New York, USA. 1990. Landscape changes in nine rural counties in Georgia, USA. Photogrammetric Engineering and Remote Sensing 56:379-386.

Turner, M. G., and R. H. Gardner, editors. 1991. Quantitative methods in landscape ecology. The analysis and interpretation of landscape heterogeneity. Springer Verlag, New York, New York, USA.

Turner, M. G., W. H. Romme, R. H. Gardner, R. V. O’Neill, and T. K. Kratz. In press. A revised concept of landscape equilibrium: disturbance and stability on scaled landscapes. Landscape Ecology.

Vitousek, P. M. 1990. Biological invasions and ecosystem processes: toward an integration of population biology and ecosystem studies. Oikos 57:7-13.

Walters, C. J. 1986. Adaptive management of renewable resources. Macmillan, New York, New York, USA.

Waterbury, J. B., S. W. Watson, R. R. L. Guillard, and L. E. Brand. 1979. Widespread occurrence of a unicellular, marine, planktonic cyanobacterium. Nature 277:293-294.

Watt, A. S. 1947. Pattern and process in the plant community. Journal of Ecology 35:1-22.

White, P. S. 1979. Pattern, process, and natural disturbance in vegetation. Botanical Review 4:229-299.

White, P. S., and S. P. Bratton. 1980. After preservation: philosophical and practical problems of change. Biological Conservation 18:241-255.

Wilcove, D. S., C. H. McLellan, and A. P. Dogbson. 1986. Habitat fragmentation in the temperate zone. Pages 237 256 in M. E. Soule, editor. Conservation biology. Sinauer, Sunderland, Massachusetts, USA.

Williams, A. B. 1988. New marine decapos crustaceans from waters influenced by hydrothermal discharge, brine, and hydrocarbon seepage. United States National Marine Fisheries Service Fishery Bulletin 86:263-287.

Wilson, E. O. 1992. The diversity of life. Belknap-Harvard Press, Cambridge, Massachusetts, USA.

Wood, C. A. 1994. Ecosystem management: achieving the new land ethic. Renewable Natural Resources Journal 12: $6-12$.

\section{APPENDIX}

Legislation as a DRIVER fOR Ecosystem MaNAgement on Federal LANDS

In the United States, much of the impetus for ecosystem management has come from legislation implemented over the past few decades to regulate and mitigate environmental impacts. While many laws specifically addressed activities on Federal lands, a significant number dealt with all lands and resources.

The Wilderness Act (1964) and Wild and Scenic Rivers Act (1968) addressed the need by the public for "an area where the earth and community of life are untrammeled by man-where man himself is a visitor who does not remain." Areas created by these special designations and set-asides, similar to National Parks, are an attempt to isolate unique resources from development or intrusion, with the assumption such isolation will preserve and protect.

In addition to laws focusing on specific resources, other laws were enacted which cut across multiple ownerships and which addressed overall quality of the environment. The Clean Water and Clean Air Acts, although initially authorized in the late 1940 s and early 1950 s, underwent substantial revision in the $1970 \mathrm{~s}, 1980 \mathrm{~s}$ and $1990 \mathrm{~s}$, in order to address emerging issues. In these acts, the public exerted its right to "protect its (the public's) interest in values which are not a part of property title ... but which can be harmed by the actions of the landowner" (Society of American Foresters 1993).

The most significant piece of legislation during this period of time may be the National Environmental Policy Act (NEPA, 1969), which fully acknowledges the tension between growing demands for natural resources and the ability to sustain those resources in its entreaty to "... encourage productive and enjoyable harmony between man and his environment; to promote efforts which will prevent or eliminate 
damage to the environment and biosphere and stimulate the health and welfare of man; to enrich the understanding of the ecological systems and natural resources important to the nation; and to establish a Council on Environmental Quality.' NEPA only applies to federal lands and actions sigificantly affecting the environment, in contrast to the Endangered Species Act (ESA, 1973), which refers to all lands and management activities. The ESA brings forward the idea of ecosystem conservation in order to protect species and "encourages the States and other interested parties . . . to develop and maintain conservation programs."

While the ESA does acknowledge the importance of eco- systems, in reality, efforts have focused on individual species, rather then developing strategies for the ecosystems within which these species survive. This is not an indictment of the process, but a recognition that ecosystem complexity was too great to address under normal regulatory processes. By the 1990 s, the large number of plants and animals listed as threatened or endangered is forcing us to develop conservation strategies within an ecosystem context. For example, strategies to address Pacific salmon stocks are incorporating watershed management. Recent events in the Pacific Northwest reflect the next step in the evolution of integrated resource management in which entire ecosystems are managed as integrated units that include individual species.

\section{APPENDIX 2}

\section{ECOSYSTEM Representation as a CONSERVATION Goal}

Ecosystem management, as an experimental and adaptive process, requires that examples of various kinds of ecosystems be protected as benchmarks or control areas for comparison to manipulated sites. Only then can effects of management practices be separated from natural processes. Thus, the familiar conservation goal of representing all ecosystem types in protected areas takes on a new urgency.

Representation is one of the most widely accepted goals of conservation. Early efforts to identify and preserve a broad spectrum of natural communities in North America were led by the Committee on the Preservation of Natural Conditions of the Ecological Society of America. In 1926, the Committee published the Naturalist's Guide to the Americas (Shelford 1926), a description of biomes and their remaining natural areas. This committee evolved into a separate organization, the Ecologists' Union, which became The Nature Conservancy in 1950. Another committee of the Ecological Society of America, the Committee for the Study of Plant and Animal Communities, assessed the adequacy of protection of ecosystems in three classes of nature sanctuaries, with the highest class being fully protected areas, with virgin vegetation and large enough to contain all the animal species in self-maintaining populations historically known to have occurred in the area (Shelford 1933, Kendeigh et al. 1950-1951).

Most strategies for representing ecosystems have had to be content with smaller natural areas that harbor less than complete biological communities (e.g., no large predators). Much of this effort has been led by The Nature Conservancy, by state natural areas programs, and by a professional society, The Natural Areas Association. The Nature Conservancy has called its community-level conservation strategy a "coarse filter" (Noss 1987) and has estimated that $85-90 \%$ of species can be protected by conserving examples of natural communities, without having to inventory and manage each species individually. This interesting idea seems reasonable but has not been tested empirically. A potentially serious limitation of the coarse filter or any representation strategy based on vegetation is that natural communities are not stable; they change as species respond more or less independently to environmental gradients in space and time. For instance, when climate changes, species track shifting habitat conditions at different rates determined by their dispersal capacities and other aspects of autecology (Davis 1981, Graham 1986).

Given the instability of natural communities, one sensible way to represent biodiversity at the ecosystem level is to maintain the full array of physical habitats and environmental gradients in an interconnected network of reserves (Noss 1987, 1992, Hunter et al. 1988). The Canadian Council on Ecological Areas is conducting an "Ecoregion Gap Analysis" (unpublished reports) to assess representation of "enduring features" defined by slope position, topography, soil type, bedrock geology, and other abiotic variables within each clas- sified ecoregion. Gaps in representation of habitats defined in this way would become priorities for protection. The U.S. Fish and Wildlife Service Gap Analysis, in contrast, is based mainly on maps of existing vegetation as determined by remote sensing. Vegetation usually provides a good surrogate for the rest of biodiversity in the short term (Scott et al. 1993). A comparison of gap analysis results based alternately on vegetation and abiotic variables would be instructive.

Practical advantages of a coarse filter include efficiency and cost-effectiveness (it is easier to deal with dozens or even hundreds of ecosystem types than thousands or millions of species) and the assumed ability to protect species we know nothing about and could not begin to inventory individually. Furthermore, a coarse filter can be applied at any level of classification hierarchy. Unfortunately, no accepted classification of communities or ecosystems exists for the United States. Ecosystems are more difficult to classify than species. At which level of classification hierarchy should natural communities be recognized, inventoried, and protected? In California, for example, should we recognize 52 wildlife habitat types (Mayer and Laudenslayer 1988), 375 natural communities (Holland 1987), or something in between? Because ecosystems at any level of classification can become endangered (Noss et al., in press), a hierarchical classification with cross-walks to other classifications is needed. The classification used in a particular case will depend on which level of hierarchy works best for the spatial scale or level of detail desired. The Nature Conservancy is developing a hierarchical classification of vegetation consistent with a global UNESCO framework and has completed a preliminary series-level (i.e., dominant plant species) classification for the western U.S. (Bourgeron and Engelking 1992).

\section{Endangered ecosystems}

The biodiversity crisis involves more than the endangerment and extinction of individual species. It also involves the loss and degradation of habitats, species assemblages, and natural processes. Such losses represent biotic impoverishment at an ecosystem level of organization. Loss of biodiversity at the ecosystem level has been most severe in the temperate zone because this region has been so intensively settled and exploited by people. As natural ecosystems decline in area or are degraded in structure, function, or composition, the species associated with them also declinehence, an ever-expanding list of endangered species. Protecting and restoring endangered ecosystems may be a more efficient way to protect rare species than managing them one by one. The associated strategy of representation takes this idea one step further by securing viable examples of all ecosystem types in a network of protected areas.

A recent U.S. Fish and Wildlife Service report (Noss et al. 1995), reviewed and synthesized data on endangered eco- 
TABLE A1. Critically endangered, endangered, and threatened ecosystems of the United States. Decline refers to outright destruction, conversion to other land uses, or significant degradation of ecological structure, function, or composition since European settlement. Estimates based on quantitative studies and qualitative assessments (see Noss et al. 1995 for references and discussion).

Critically endangered ( $>98 \%$ decline)

Old-growth and other virgin stands in the eastern deciduous forest biome

Spruce-fir forest in the southern Appalachians

Red and white pine forests (mature and old-growth) in Michigan

Longleaf pine forests and savannas in the Southeastern Coastal Plain

Pine rockland habitat in South Florida

Loblolly/shortleaf pine-hardwood forests in the West Gulf Coastal Plain

Arundinaria gigantea canebrakes in Southeast

Tallgrass prairie east of Missouri River and on mesic sites across range

Bluegrass savanna-woodland and prairies in Kentucky

Black Belt prairies in Alabama and Mississippi and Jackson Prairie in Mississippi

Oak savanna in Midwest

Wet and mesic coastal prairies in Louisiana

Lakeplain wet prairie in Michigan

Sedge meadows in Wisconsin

Hempstead Plains grasslands on Long Island, New York

Serpentine barrens, maritime heathland, and pitch pineheath barrens in New York

Coastal rocky headlands in New Hampshire

Prairies (all types) and oak savannas in Willamette Valley and foothills of Coast Range, Oregon

Palouse prairie (Washington, Oregon, and Idaho, plus similar communities in Montana)

Native grasslands (all types) in California

Alkali sink scrub in southern California

Coastal strand in southern California

Ungrazed sagebrush steppe in Intermountain West

Basin big sagebrush in Snake River Plain of Idaho

Atlantic white cedar stands in the Great Dismal Swamp of Virginia and North Carolina, and possibly across entire range

Streams in Mississippi Alluvial Plain

Endangered (85-98\% decline)

Old-growth and other virgin forests in regions and states other than those listed above, except Alaska

Mesic limestone forest and barrier island beaches in Maryland

Coastal plain Atlantic white cedar swamp, maritime oakholly forest, maritime red cedar forest, marl fen, marl pond shore, and oak openings in New York

Coastal heathland in southern New England and Long Island

Pine-oak-heath sandplain woods and lake sand beach in Vermont

Floodplain forests in New Hampshire

Red spruce forests in central Appalachians (West Virginia)

Upland hardwoods in the Coastal Plain of Tennessee

Lowland forest in southeastern Missouri

High-quality oak-hickory forest on the Cumberland Plateau and Highland Rim of Tennessee

Limestone cedar glads in Tennessee

Wet longleaf pine savanna and eastern upland longleaf pine forest in Louisiana

Calcareous prairie, Fleming glade, shortleaf pine/oakhickory forest, mixed-hardwood-loblolly pine forest, eastern xeric sandhill woodland, and stream terrace sandy woodland/savanna in Louisiana
TABle A1. Continued.

Slash pine forests in southwestern Florida

Red and white pine forests in Minnesota

Coastal redwood forests (California)

Riparian forests in California, Arizona, New Mexico

Coastal sage scrub (especially maritime) and coastal mixed chaparral in Southern California

Dry forest on main islands of Hawaii

Native habitats of all kinds in lower delta of Rio Grande River, Texas

Tallgrass prairie (all types combined)

Native shrub and grassland steppe in Oregon and Washington

Low elevation grasslands in Montana

Gulf Coast pitcher plant bogs

Pocosins (evergreen shrub bogs) and ultramafic soligenous wetlands in Virginia

Mountain bogs (Southern Appalachian bogs and Swamp forest-bog complex) in Tennessee and North Carolina

Upland wetlands on the Highland Rim of Tennessee

Saline wetlands in eastern Nebraska

Wetlands (all types combined) in south-central Nebraska, Missouri, Iowa, Illinois, Indiana, Ohio, California

Marshes in Carson-Truckee area of western Nevada

Low elevation wetlands in Idaho

Woody hardwood draws, glacial pothole ponds, and peatlands in Montana

Vernal pools in Central Valley and Southern California

Marshes in Coos Bay area of Oregon

Freshwater marsh and coastal salt marsh in Southern California

Seasonal wetlands of San Francisco Bay, California

Large streams and rivers in all major regions

Aquatic mussel beds in Tennessee

Submersed aquatic vegetation in Chesapeake Bay, Maryland and Virginia

Mangrove swamps and salt marsh along the Indian River Lagoon, Florida

Seagrass meadows in Galveston Bay, Texas

Threatened (70-84\% decline)

Riparian forests nationwide (other than in regions listed above), including southern bottomland hardwood forests

Xeric habitats (scrub, scrubby flatwoods, sandhills) on Lake Wales Ridge, Florida

Tropical hardwood hammocks on central Florida keys

Alvar grassland, calcareous pavement barrens, dwarf pine ridges, mountain spruce-fir forest, inland Atlantic white cedarswamp, freshwater tidal swamp, inland salt marsh, patterned peatland, perched bog, pitch pineblueberry peat swamp, coastal plain poor fens, rich graminoid fen, rich sloping fen, and riverside ice meadow in New York

Saline prairie, western upland longleaf pine forest, live oak-pine-magnolia forest, western xeric sandhill woodland, slash pine-pond cypress/hardwood forest, wet and mesic spruce pine-hardwood flatwoods, wet mixed hardwood-loblolly pine flatwoods, and flatwoods ponds in Louisiana

Northern hardwood forest, aspen parkland, and jack pine forests in Minnesota

Old-growth ponderosa pine forests in northern Rocky Mountains, Intermountain West, and eastern Cascades Mountains

Maritime-like forests in Clearwater Basin of Idaho

Woodland and chaparral on Santa Catalina Island

Southern tamarack swamp in Michigan

Wetlands (all kinds) in Connecticut, Maryland, Arkansas, Kentucky

Marshes in Puget Sound region, Washington

Cienegas (marshes) in Arizona

Coastal wetlands in California 
systems in the United States. Ecosystems were defined generally and included vegetation types, plant associations, natural communities, and habitats defined by floristics, structure age, geography, condition, and other ecologically relevant factors. Data were variable in quality, but for each ecosystem type, the most reliable and recent estimates of loss or degradation were cited. All estimates of ecosystem losses $>50 \%$ are reported, as well as some other documented losses (for example, of wetlands) of $<50 \%$ for comparison.

Noss et al. (1995) identified those ecosystems at greatest risk. Grasslands and savannas stand out in the top category of "critically endangered," but in the larger list wetlands and forests appear just as imperiled. Aquatic and nearshore marine systems, though underrepresented in terms of number of "types" imperiled, have been seriously degraded throughout the nation. For example, $81 \%$ of fish communities nationwide are adversely affected by human activities and $98 \%$ of streams are degraded enough to be unworthy of federal designation as wild or scenic rivers (see references in Noss et al. 1995). Losses of all kinds of ecosystems have been most severe in the South, Northeast, Midwest, and California, but no region of the U.S. has escaped damage.

Endangered and threatened ecosystems have declined to their present condition because no comprehensive program to conserve ecosystems has been in place in the United States. Ecosystem management can contribute to ecosystem conservation if it places high priority on identifying and mapping ecosystem types that have declined greatly in extent or quality, then puts in place programs to protect and restore these types. Many scientists have suggested that some kind of "endangered ecosystems act" or similar legislation may be needed to achieve ecosystem conservation in the U.S. (Ehrlich and Ehrlich 1986, Noss and Harris 1986, Hunt 1989, Orians 1993). 